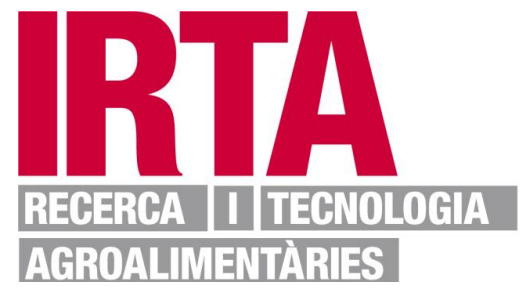

This is a post-peer-review, pre-copyedit version of an article published in Irrigation Science. The final authenticated version is available online at:

https://doi.org/10.1007/s00271-018-0591-y

Document downloaded from:

IRTAPubpro

Open digital archive 


\title{
Evapotranspiration Estimates Derived Using Thermal-Based Satellite Remote Sensing and Data Fusion for Irrigation Management in California Vineyards
}

Kyle R. Knipper ${ }^{1}$, William P. Kustas ${ }^{1}$, Martha C. Anderson ${ }^{1}$, Maria Mar Alsina ${ }^{6}$, Joseph G. Alfieri ${ }^{1}$, John H. Prueger ${ }^{2}$, Christopher R. Hain ${ }^{3}$, Feng Gao ${ }^{1}$, Yun Yang ${ }^{1}$, Lynn G. McKee ${ }^{1}$, Hector Nieto ${ }^{4}$, Lawrence E. Hipps ${ }^{5}$, Luis Sanchez ${ }^{6}$

${ }^{1}$ USDA ARS, Hydrology and Remote Sensing Laboratory, Beltsville, MD 20705-2350 USA

${ }^{2}$ USDA ARS, National Laboratory for Agriculture and the Environment, Ames, IA 50011 USA

${ }^{3}$ NASA Marshall Space Flight Center, Huntsville, AL 35811 USA

${ }^{4}$ Institute for Food and Agricultural Research \& Technology, Parc de Gardeny, Edifici

Fruitcentre, 25003 Lleida, Spain

${ }^{5}$ Plants, Soils and Climate Department, Utah State University, Logan, UT 84322-4820 USA

${ }^{6}$ E.\&J. Gallo Winery, Viticulture, Chemistry and Enology, Modesto, CA 95354 USA

Corresponding author: Kyle R. Knipper; kyle.knipper@ars.usda.gov; 301-504-8412

\begin{abstract}
Irrigation in the Central Valley of California is essential for successful wine grape production. With reductions in water availability in much of California due to drought and competing water use interests, it is important to optimize irrigation management strategies. In the current study, we investigate the utility of satellite-derived maps of evapotranspiration (ET) and the ratio of actual to reference ET ( $\left.f_{\text {RET }}\right)$ based on remotely sensed land surface temperature (LST) imagery for monitoring crop water use and stress in vineyards. The Disaggregated Atmosphere Land EXchange Inverse (ALEXI/DisALEXI) surface energy balance model, a multi-scale ET remote sensing framework with operational capabilities, is evaluated over two Pinot noir vineyard sites in central California that are being monitored as part of the Grape Remote sensing Atmospheric Profile and Evapotranspiration eXperiment (GRAPEX). A data fusion approach is employed to combine ET timeseries retrievals from multiple satellite platforms to generate estimates at both the high spatial (30m) and temporal (daily) resolution required for field-scale irrigation management. Comparisons with micrometeorological data indicate reasonable model performance, with mean absolute errors of $0.59 \mathrm{~mm} \mathrm{~d}^{-1}$ in ET at the daily timestep and minimal bias. Values of $f_{R E T}$ agree well with tower observations and reflect known irrigation.

Spatiotemporal analyses illustrate the ability of ALEXI/DisALEXI/data fusion package to characterize heterogeneity in ET and $\mathrm{f}_{\text {RET }}$ both within a vineyard and over the surrounding landscape. These findings will inform the development of strategies for integrating ET mapping time series into operational irrigation management framework, providing actionable information regarding vineyard water use and crop stress at the field and regional scale and at daily to multiannual timescales.
\end{abstract}




\section{Introduction}

Water management is a critical aspect of successful grape production in California's Central Valley, which represents over 400,000 hectares valued at approximately 6 billion dollars (California Department of Food and Agriculture \& USDA National Agricultural Statistics Service 2016). Despite competing water use interests and a reduction in water availability over much of California due to recent long-term droughts, vineyard acreage and production continues to increase, with acreage devoted to wine grapes increasing by 12,950 hectares between years 2013 and 2016 (California Department of Food and Agriculture \& USDA National Agricultural Statistics Service 2017). As such, there is significant interest in developing efficient water management strategies for these viticulture production systems.

The adoption of an appropriate and efficient irrigation strategy for a specific vineyard is predicated on understanding and controlling the vine water stress throughout the season (Girona et al. 2009; van Leeuwen et al. 2009; Basile et al. 2011). Moderate vine water stress, achieved through the practice of deficit irrigation can improve the composition/quality of grapes used in wine production (Williams and Matthews 1990; Williams et al. 1994). The standard indicator for vine water stress is the leaf water potential $\left(\Psi_{\mathrm{L}}\right)$, commonly measured using a pressure chamber. In some cases, pressure bomb measurements are used in scheduling irrigation for commercial vineyards (Girona et al. 2006). However, this practice requires individual leaf measurements, limiting its suitability for application over large heterogeneous areas. Techniques for mapping $\Psi_{\mathrm{L}}$ have been developed using high resolution thermal imagery to isolate plant canopy temperatures (Bellvert et al., 2016). This technique could be used for mapping variability in vine stress across vineyards; however, it would be challenging to provide this information on a routine basis over large regions and may require calibration for different climates and vine varieties.

An additional tool for monitoring water stress and use in vineyards is measurement of evapotranspiration (ET), which quantifies water loss from the vine and surface to the atmosphere. Numerous studies have explored various methods and techniques to measure vineyard ET or water use, including lysimeters (Johnson et al. 2005; Azevedo et al. 2008; Netzer et al. 2009), eddy covariance (Spano et al. 2000; Ortega-Farias et al. 2010; Rodriguez et al. 2010), heat pulse or heat balance (Trambouze et al. 1998; Yunusa et al. 1997; Intrigliolo et al. 2009; Zhang et al. 2010), surface renewal energy balance (Castellvi and Snyder 2010; Moratiel and Martinez-Cob 2012), Bowen ratio energy balance (Yunusa et al. 2004; Teixeira et al. 2007; Zhang et al. 2011), soil water balance (Singleton and Maudsley 1996; Fooladmand and Sepaskhah 2009; Cancela et al. 2012), and the most common and simplest approach, the FAO-56 method (Allen et al. 1998). However, like the leaf water potential measurement method, these approaches simply provide point measurements that are difficult to extrapolate over larger areas or fields, and fail to indicate in-field spatial variability (Teixeira et al. 2007). Such spatial variability limits the effective use of irrigation water. Uniform irrigation across a vineyard with variable biomass and soil texture, implying differences in plant growth and water requirements, will result in the over- or under-watering in these anomalous sections within the vineyard. This will result in variability in vegetative growth across the vineyard, and result in non-uniform yield and grape composition/quality (Bramley and Hamilton 2004; Bramley et al. 2005; Bellvert et al. 2012). Errors are further compounded when extrapolating to vineyards outside the area of in-situ ET data collection. 
Satellite remote sensing technology offers the possibility of providing routine spatial information useful for determining sub-field and inter-field scale heterogeneity in plant conditions and water use. Satellite retrievals of land-surface temperature (LST), derived from thermal-infrared (TIR) imagery, have been shown to be particularly useful for estimating ET and plant stress due to the sensitivity of soil and canopy temperatures to variable soil moisture availability (Moran 2003). Several TIR-based ET mapping algorithms have been developed over the past few decades (e.g. Bastiaanssen et al. 1998; Su 2002; Allen et al. 2007; Anderson et al. 1997). Due to significant uncertainties associated with determining accurate atmospherically and emissivity corrected surface temperature data, most TIR-based models use relative measures of LST variability to parameterize ET estimates rather than the absolute LST values (Anderson et al. 1997; 2012). This is accomplished either through using an end-member pixel scaling method (spatial variability) or a time-differential method (temporal variability). For example, the Surface Energy Balance Algorithm for Land (SEBAL; Bastiaanssen et al. 1998) and the Mapping Evapotranspiration with Internalized Calibration (METRIC; Allen et al. 2007) methods use TIR end-member pixels within a satellite image to represent limiting (minimal ET; hot pixel) and non-limiting (potential ET; cold pixel) moisture conditions. The Atmosphere Land Exchange Inverse (ALEXI; Anderson et al. 1997; 2007a; 2007b) surface energy balance model uses the time-differential approach, relating changes in morning LST derived from geostationary satellites to surface moisture availability and latent heat flux. ALEXI is based on the TwoSource Energy Balance (TSEB) land surface representation originally described by Norman et al. (1995). The TSEB can also be used to downscale ALEXI fluxes to finer, subfield scales using an associated flux disaggregation technique (DisALEXI; Norman et al. 2003).

Recent studies have demonstrated the utility of TIR-based ET approaches for monitoring water use and stress within vineyards (Semmens et al. 2016; Xia et al. 2016). Specifically, Semmens et al. (2016) applied the ALEXI/DisALEXI modeling system, integrated with a data fusion methodology (Gao et al. 2006), to estimate daily ET at 30m spatial resolution over two Pinot noir vineyards near Lodi in the Central Valley of California for the 2013 growing season, demonstrating good agreement with ground-based flux measurements. Moreover, Xia et al. (2016) evaluated TSEB model performance over these two vineyards at high spatial resolution $(\leq$ $1 \mathrm{~m}$ ) using thermal and multispectral remote sensing data from low-altitude aircraft over the same two vineyards. Results indicate that the TSEB can derive reliable ET patterns at sub-field scale under a wide range of environmental conditions.

The current study expands upon results presented in Semmens et al. (2016), extending the analysis to multiple years to promote a comprehensive understanding of seasonal flux dynamics within the unique canopy architecture of vineyards, especially during the early spring season when timing of the initiation of irrigation and subsequent water use estimates can have significant errors. In this study, daily 30m ET maps over the Lodi vineyard landscape are evaluated over the period 2013-2016, including an extended period of severe drought when water resources in the Central Valley became increasingly limited. An analysis is also included on the ratio of actual to reference ET ( $f_{\text {RET }}$ ), an indicator of crop moisture and stress conditions, and its linkages on both spatial and temporal scales to criteria used in irrigation decision making. The current study aims to demonstrate the utility of remotely sensed ET and $f_{\text {RET }}$ mapping time series in support of an operational irrigation management framework, supplying reliable spatiotemporal 
information on vineyard water use and crop stress at the field and regional scale and at daily to annual timescales.

\section{Materials and Methods}

\section{Study Area}

The model study domain includes two vineyard sites located in the Central Valley of California near the town of Lodi, using data collected as part of the USDA-ARS Grape Remote sensing Atmospheric Profile and Evapotranspiration eXperiment (GRAPEX) (Kustas et al. 2018). Both the northern (site 1) and the southern (site 2) vineyards are planted with Pinot noir vines trained on quadrilateral cordons with drip irrigation installed. Both sites have vine heights that vary between 2 and $2.5 \mathrm{~m}$, with space between rows of $3.3 \mathrm{~m}$, space between vines of $1.5 \mathrm{~m}$, and an east-west row orientation. The northern site has an area of 35 ha with vines planted in 2009 . The southern site is smaller and less mature, with an area of 21 ha and vines planted in 2011, resulting in lower biomass/leaf area than the northern field. In these plots, vines typically leaf out in late March, grow through late August, with grape harvest occurring in early September. Flux tower were installed in 2013 approximately half-way north-south along the eastern edge of each field, located to maximize fetch as the predominant wind direction is from the west during the growing season. These towers continue to operate through the 2017 growing season.

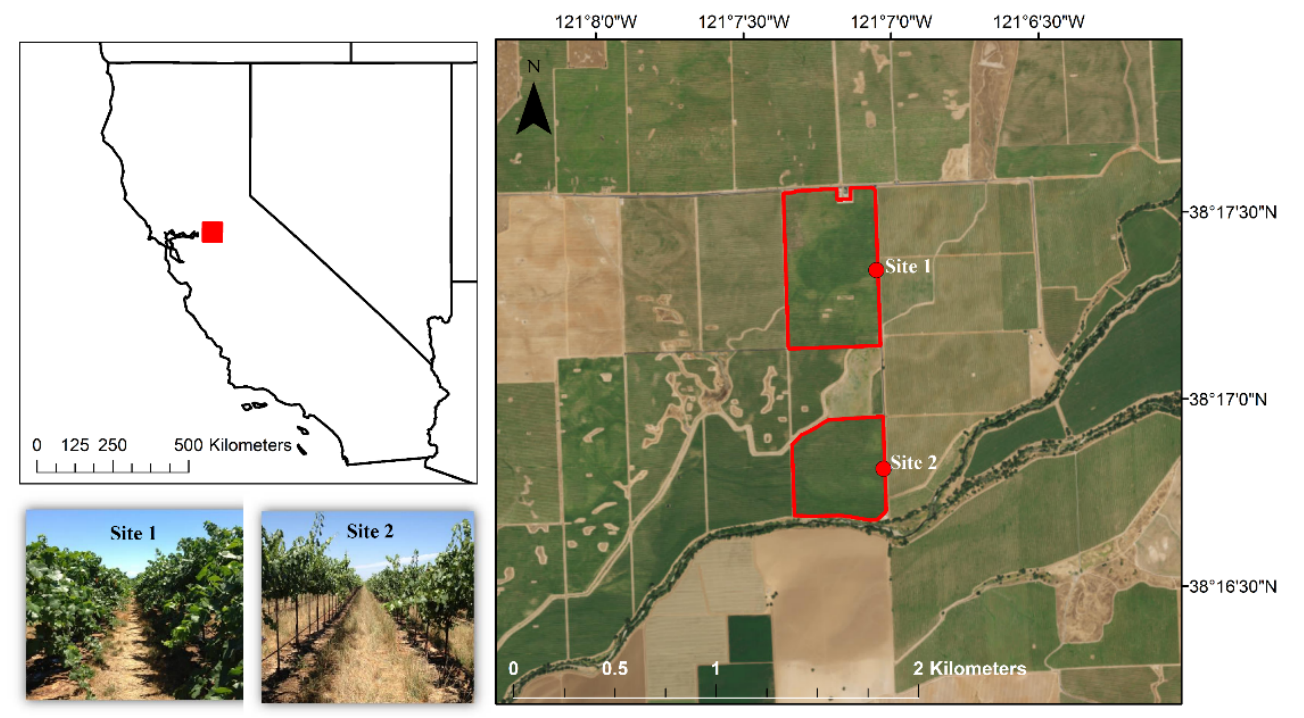

Fig. 1 Location of study area. Red boxes represent the northern and southern vineyards and red dots represent the location of the flux towers. The two photos of the northern (Site 1) and southern (Site 2) vineyard blocks were taken on August 6 ${ }^{\text {th }}, 2013$.

\section{Field Measurements}

Micrometeorological and biological field measurements collected during GRAPEX are designed to serve as validation data for models developed to estimate ET and component vine and interrow fluxes, detect stress, and monitor biomass development and root zone soil water availability. Both vineyards are equipped with identical micrometeorological instrumentation and started recording in late March of 2013. Measurements include turbulence and mean profile 
measurements of wind, surface energy balance flux estimates, temperature and water vapor, as well as ground-based biophysical measurements such as leaf area index (LAI).

The eddy covariance (EC) systems include a Campbell Scientific, Inc. EC150 water vapor/carbon dioxide sensor and a CSAT3 three-dimensional sonic anemometer. Both instruments are mounted $5 \mathrm{~m}$ above local ground level (a.g.1.) facing due west, collecting data at $20 \mathrm{~Hz}$ producing $15 \mathrm{~min}$ averages. Additional instrumentation includes a four-component radiometer (CNR-1, Kipp and Zonen, Delft, Netherlands) mounted $6 \mathrm{~m}$ a.g.1., upward and downward facing quantum sensors (LI-190, Li-Cor, Lincoln, Nebraska) mounted $6 \mathrm{~m}$ a.g.1., a combined humidity and temperature sensor (HMP45C, Vaisala, Helsinki, Finland) mounted $5 \mathrm{~m}$ a.g.l., two thermal infrared thermometers (SI-111, Campbell Scientific) mounted $2.5 \mathrm{~m}$ a.g.1. used to measure both surface and canopy temperature, a tipping bucket rain gauge (TE525, Texas Electronics, Dallas, Texas), and five soil heat flux plates (HFT-3, Radiation Energy Balance Systems, Bellevue, Washington) buried cross-row at a depth of $8 \mathrm{~cm}$. Each heat flux plate includes two thermocouples buried at depths of 2 and $6 \mathrm{~cm}$ and a soil moisture sensor (HydraProbe, Stevens Water Monitoring System, Portland, Oregon) buried at $5 \mathrm{~cm}$ depth. ${ }^{1}$

Post-processing of the $20 \mathrm{~Hz}$ eddy covariance data for computing sensible and latent heat fluxes is described by Alfieri et al. (this issue). Energy balance flux measurements used in this study were collected between April 16, 2013 and October 19, 2016. During this period, typical closure ratios were on the order of 0.91 for Site 1 and 0.88 for Site 2. Original and closure-adjusted latent heat flux (LE) measurements were compared to modeled LE estimates to determine degree of agreement between measured and modeled fluxes. Since daily totals are used for model validation, observed fluxes were corrected for closure errors using the residual (RE) method as opposed to Bowen Ratio (BR) method (which often yields spurious results for nighttime conditions) described in Twine et al. (2000).

Measurements of water applied through irrigation began in 2015 and are made using an assemblage of pressure switches and Onset HOBO data loggers (Onset Computer Corporation, Bourne, MA). Irrigation events are recorded as the time difference between the beginning and end of irrigation, with events lasting roughly 5 hours on average between sites. The amount of irrigation applied in liters per vine is calculated using an average irrigation pump rate and vine/row spacing data provided by vineyard managers.

Yield maps for 2013 through 2016 harvest in both north and south vineyards are provided by E\&J Gallo Winery using Advanced Technology Viticulture (ATV, Joslin, Australia) yield monitoring systems and a cleanup script used to convert mass flow units into tons per hectare, eliminate outliers, and normalized across harvesters. Yield data greater than three standard deviations from the mean are omitted. Yield maps are interpolated to a $3 \mathrm{~m}$ grid using Vesper Spatial Prediction Software for Precision Agriculture (Whelan et al. 2002).

\section{Multi-scale ET modeling system}

\footnotetext{
${ }^{1}$ The use of trade, firm, or corporation names in this article is for the information and convenience of the reader. Such use does not constitute official endorsement or approval by the US Department of Agriculture or the Agricultural Research Service of any product or service to the exclusion of others that may be suitable.
} 
The multi-scale ET modeling system used here downscales regional coarse-scale fluxes from the ALEXI surface energy balance model (Anderson et al. 1997; 2007a; 2007b; Mecikalski et al. 1999) to finer spatial scales. ALEXI exploits the high temporal resolution afforded by geostationary satellites to measure the morning rate of land surface temperature (LST) rise, which is used to guide partitioning of the surface energy budget. Time-differential LST measurements provide the added benefit of being less sensitive to errors in temperature retrieval due to atmospheric and emissivity correction (Anderson et al. 1997).

ALEXI is based on the Two-Source Energy Balance (TSEB) model, first developed by Norman et al. (1995), and later refined through improved parameterizations in Kustas and Norman (1999). The TSEB model partitions surface temperature into soil and vegetation components, which are then used to solve the surface-energy budget for the soil, canopy and combined system associated with the mixed scene:

$$
\left(R n_{s}+R n_{c}\right)-G=\left(H_{s}+H_{c}\right)+\left(\lambda E_{s}+\lambda E_{c}\right)
$$

where $R n$ is net radiation $\left(\mathrm{W} / \mathrm{m}^{2}\right), H$ is the sensible heat flux $\left(\mathrm{W} / \mathrm{m}^{2}\right), G$ is the soil heat flux $\left(\mathrm{W} / \mathrm{m}^{2}\right)$ and $\lambda E$ is the latent heat flux $\left(\mathrm{W} / \mathrm{m}^{2}\right)$. Subscripts ' $s$ ' and ' $c$ ' represent fluxes associated with the soil and canopy scene components, respectively. The TSEB uses an estimate of local vegetation cover fraction to partition the composite surface temperature measurement into soil and canopy temperatures, which are used to constrain net radiation and sensible heat flux, defined by the surface-to-air temperature gradient. The $G$ term is parameterized in as a fraction of the net radiation at the soil surface $\left(R n_{s}\right)$. Canopy transpiration, $\lambda E_{c}$, is estimated using a modified Priestley-Taylor approach (Priestley and Taylor, 1972) which responds to signals of vegetation stress conveyed by the surface temperature measurement, while soil evaporation $\lambda E_{s}$ is computed as the residual to the energy balance equation.

The TSEB model is applied at two times during the atmospheric boundary layer (ABL) growth phase, at approximately $1.5 \mathrm{hr}$ after local sunrise $\left(\mathrm{t}_{1}\right)$ and $1.0 \mathrm{hr}$ before local noon $\left(\mathrm{t}_{2}\right)$. A simple slab model of ABL development (McNaughton and Spriggs, 1986) is used to provide a means for surface energy closure by relating the rise in air temperature in the mixed layer over the time interval $\left(t_{1} t_{1} t_{2}\right)$ to the time-integrated influx of $H$ from the surface (Anderson et al. 1997). This approach allows near-surface air temperature to be computed internally, eliminating the need for an a priori specification of air temperature boundary conditions to the sensible heat flux computation.

Daily latent heat flux is derived using ALEXI-retrieved latent heat flux estimates at $\mathrm{t}_{2}$ and upscaled to $24 \mathrm{hrs}$ using the ratio of instantaneous to daily insolation:

$\lambda E_{\text {day }}=\frac{\lambda E_{t_{2}}}{R_{S_{t 2}}}\left(R_{S_{24}}\right)$

where $\lambda E_{t_{2}}$ is the latent heat at $\mathrm{t}_{2}, R_{S_{t 2}}$ is the insolation rate at $\mathrm{t}_{2}$, and $R_{S_{24}}$ is the time-integrated daily insolation rate. This insolation technique has proven generally reliable, with lower bias and 
sensitivity to errors in retrieval estimates when compared to other techniques (Cammalleri et al. 2014a). Daily net radiation $\left(R_{n_{24}}\right)$ maps are derived using an approach described in Anderson et al. (2012), daily $G$ maps are computed by integrating the Santanello equation over daylight hours (Santanello and Friedl 2003), and daily $H$ values are computed as the residual. All fluxes are expressed in $\mathrm{MJ} \mathrm{m}^{-2} \mathrm{~d}^{-1}$. The daily latent heat is converted to daily ET (in units of $\mathrm{mm} \mathrm{d}^{-1}$ ) by dividing by the latent heat of vaporization $\lambda$.

Missing pixels within the ALEXI ET maps, due either to cloud cover or missing or low-quality input data, are gap filled by conserving the ratio of actual ET to daily insolation $\left(f_{\text {sun }}\right)$ over time at each pixel. The timeseries of clear-sky $f_{\text {sun }}$ is filtered, smoothed and gap-filled for each pixel using a Savitzky-Golay filter, designed to reduce noise while preserving signals associated with changes in surface moisture conditions. Missing pixels within the daily ET map are then recovered by multiplying the gap-filled $\mathrm{f}_{\text {sun }}$ fields by the daily scaling flux (insolation) maps.

ALEXI is run operationally by the National Oceanic and Atmospheric Association (NOAA) at 8 $\mathrm{km}$ spatial resolution over North America as part of the Geostationary Operational Environmental Satellite (GOES) Evapotranspiration and Drought (GET-D) system. GET-D produces daily ET and an ET-based Evaporative Stress Index (ESI) using radiometric temperature data retrieved from GOES East and West thermal imagery. The ESI describes standardized anomalies in the actual-to-reference ET ratio $\left(f_{\mathrm{RET}}\right)$, using the Penman-Monteith (FAO-56) reference ET for grass (1998). The ESI is an indicator of agricultural drought reflecting impacts on crop water use, and has been shown to provide early warning of deteriorating crop conditions (Anderson et al. 2011, 2013; Otkin et al. 2013; Otkin et al. 2014). A $4 \mathrm{~km}$-resolution grid is also maintained for research purposes and allows assessment of ESI and ET at the regional scale over the continental U.S. (CONUS).

\section{DisALEXI}

Due to its reliance on high temporal frequency TIR imagery, here obtained from geostationary satellites, ALEXI is constrained to operate on coarser spatial scales on the order of a few kilometers. To map flux distributions at higher spatial resolution, an associated spatial disaggregation technique known as DisALEXI (Norman et al. 2003; Anderson et al. 2004; 2012) can be implemented using higher resolution TIR imagery from polar orbiting instruments or from airborne platforms. DisALEXI operates by running the TSEB model over each ALEXI pixel area within a given modeling domain using the higher spatial resolution vegetation cover and surface radiometric temperature information. For this application of TSEB, the air temperature boundary condition (set at a nominal blending height of $50 \mathrm{~m}$ ), is iteratively adjusted at the ALEXI pixel scale until the DisALEXI daily ET fluxes converge to the ALEXI value on average over that pixel. This ensures consistency between the ALEXI and DisALEXI flux fields. Further description can be found in Anderson et al. (2012), and Cammalleri et al. (2013, 2014a).

\section{ET data fusion}

In this study, DisALEXI was used to generate ET map timeseries at moderate resolution $(1 \mathrm{~km})$ and near daily timesteps using thermal and reflectance data from the MODerate Resolution 
Imaging Spectroradiometer (MODIS). Higher resolution $(30 \mathrm{~m})$ maps were created with periodic Landsat datasets, with thermal band data sharpened to the 30-m resolution of the reflectance bands using the Data Mining Sharpener tool developed by Gao et al. (2012a). These two timeseries were then fused using the Spatial and Temporal Adaptive Reflectance Fusion Model (STARFM; Gao et al. 2006) to create daily maps of ET at 30-m resolution.

In short, STARFM predicts Landsat-resolution ET maps on MODIS acquisition dates by developing spatially distributed weighting factors representing the spectral similarity and temporal difference between observed Landsat/MODIS maps collected on the same day. These weighting factors are then used in the disaggregation of MODIS images on days when Landsat is not available, resulting in daily Landsat-scale ET maps. For more information, the reader is referred to Gao et al. (2006), Cammalleri et al. (2013; 2014a) and Semmens et al. (2016).

\section{Model inputs}

LST inputs for the 4-km ALEXI simulations over CONUS were obtained $11 \mu \mathrm{m}$ brightness temperature observations from the GOES-EAST (at $75^{\circ} \mathrm{W}$ ) and GOES-WEST (at $105^{\circ} \mathrm{W}$ ) Imager instruments. Raw brightness temperature values are atmospherically corrected using atmospheric profiles of temperature, as described in French et al. (2003). Vegetation cover fraction, used to partition LST between soil and canopy temperatures, is computed from MODIS leaf area index (LAI) product (see below), aggregated to $4 \mathrm{~km}$ and interpolated to daily timesteps.

Landsat 8 (L8) data between April 16, 2013 and October 19, 2016 were collected over the study area, which is in the overlap of two scenes (path 44/row 33 and path 43/row 33). A total of 87 mostly clear scenes were processed. Landsat thermal band data at native resolution $(100 \mathrm{~m})$ were atmospherically corrected using MODTRAN (Berk et al. 1989) then sharpened to $30 \mathrm{~m}$ resolution to match Landsat optical bands using the data mining sharpener (DMS) approach (Gao et al. 2012a). Atmospherically corrected shortwave reflectance data were directly downloaded from the U.S. Geological Survey (USGS) Earth Explorer website (http://earthexplorer.usgs.gov). These reflectance products were used to derive 30-m maps of LAI using regression tree analysis trained by MODIS $1 \mathrm{~km}$ LAI data, as described in Gao et al. (2012b).

MODIS daily LAI maps were generated from the 4-day composite (MCD15A3, Collection 5) products and a procedure outlined in Gao et al. (2008), where the 4-day products are smoothed and gapfilled to daily timesteps using the TIMESAT algorithm for analyzing satellite time-series data for seasonality and other temporally dynamic vegetation properties (Jönsson and Eklundh, 2004). Input MODIS albedo maps were generated from the Solar Zenith Angle (SZN)-extended MODIS/Terra + Aqua 30 arc sec Global Gap-Filled Snow-Free Bidirectional Reflectance Distribution Function (BRDF) (MODIS BRDF/Albedo CMG Gap-Filled Snow-Free Product MCD43GF V005) parameters product (University of Massachusetts Boston, Dr. Crystal Schaaf). MODIS LST maps were generated using the Terra instantaneous swath product (MOD11_L2) and geolocation product (MOD03) to obtain correct georegistration. LST maps were sharpened using DMS (MODIS $1 \mathrm{~km}$ composite NDVI as input) to reduce the bowtie effect due to off-nadir pixel smearing (Cammalleri et al. 2014b, Semmens et al. 2016). 
Meteorological inputs to ALEXI/DisALEXI include hourly solar radiation, air temperature, wind speed and vapor pressure. These data were obtained from the National Centers for Environmental Prediction (NCEP) Climate Forecast System Reanalysis (CFSR) data set (Dee et al. 2013). All fields were mapped to the $4 \mathrm{~km}$ ALEXI grid and converted to each sensor's projection at both daily and overpass times for ingestion into DisALEXI.

ALEXI/DisALEXI also requires landcover class to specify surface roughness parameters and vegetation optical properties (Anderson et al. 2007a). The ALEXI model uses the University of Maryland (UMD) global land cover dataset at $1 \mathrm{~km}$ resolution, based on observations from the AVHRR (Hansen et al. 2000). Higher resolution MODIS and Landsat disaggregation requires the $30 \mathrm{~m}$ National Land Cover Dataset (NLCD) (Fry et al. 2011). For MODIS, the NLCD map was upscaled to $1 \mathrm{~km}$ resolution using the majority class within each MODIS pixel.

Prior evaluation of ALEXI/DisALEXI over California vineyards indicate a small wet bias in modeled fluxes during the cold season (Semmens et al. 2016). The current study incorporates a generalized second order empirical correction factor based on the day of year (DOY) to adjust this bias (Anderson et al. 2018). Minimal correction is applied during the mid-season, with the largest corrections being applied during the beginning and ending of the year, causing minimal impact to seasonal total estimates. For more information, the reader is referred to Anderson et al. (2018).

\section{Results}

\section{Model evaluation on Landsat dates}

The accuracy of the fused daily 30-m ET timeseries depends largely on the fidelity in energy balance partitioning achieved on dates of clear Landsat overpasses, while the MODIS ET data effectively serve to inform interpolation between Landsat dates. To evaluate performance on these key tie-points, modeled daytime flux estimates derived using DisALEXI on Landsat overpass dates are compared to EC observations in Fig. 2, with statistical metrics of agreement provided in Table 1. The modeled flux estimates have been averaged over a 3-by-3 pixel area ( 90 $\mathrm{x} 90 \mathrm{~m}$ ) shifted west from the tower center to avoid non-characteristic pixels over the adjacent road. Model estimates of latent heat flux (LE) have been compared to measured fluxes both as observed and closed using the RE method, as described in the Field Measurements section. This enables an evaluation of closure impacts on the assessment of model performance.

Simulated daytime fluxes derived from DisALEXI generally align along the one-to-one line (Fig. 2 ), indicating reasonable partitioning by the TSEB. Insolation and net radiation, defining energy available for partitioning, agree well with in situ measurements. A few days with higher discrepancies reflect errors in the CFSR insolation inputs, related to misrepresentation of clouds in the reanalysis data. Future implementation over North America will test use of NOAA's GOES Surface and Insolation Products (GSIP; Laszlo et al. 2008) as a near real time input data source. Preliminary investigation shows that these hourly, 20-km satellite derived estimates developed by Diak et al. (2017) better capture local variability in solar irradiance over the northern vineyard (Anderson et al. 2018), although some regional calibration may be required. 

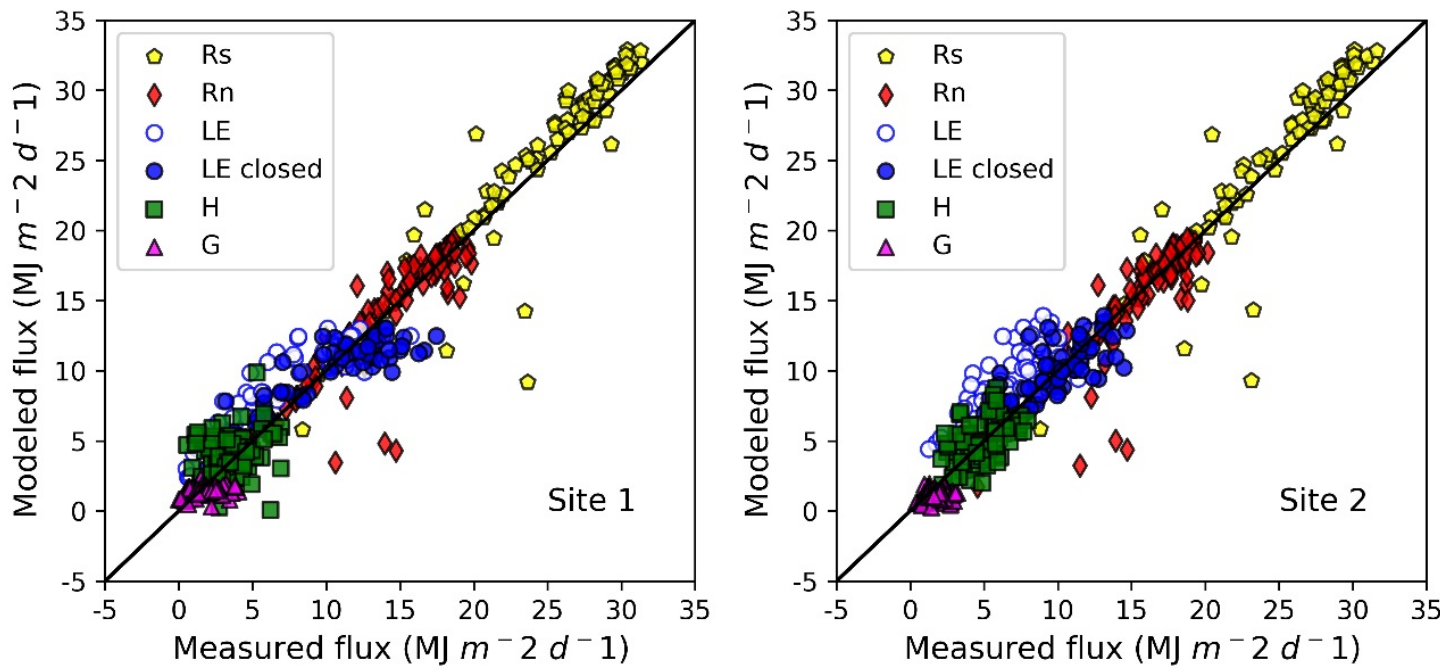

Figure 2. Scatterplots comparing measured (observed) and modeled daytime fluxes obtained from DisALEXI on Landsat overpass dates between April 16, 2013 and October 19, 2016 at site 1 (left panel) and site 2 (right panel).

Model performance for the 2013-2016 period is similar to that reported by Semmens et al. (2016), where MAE errors in daily LE of $\sim 1.2 \mathrm{MJ} \mathrm{m}^{-2} \mathrm{~d}^{-1}$ were obtained for Landsat overpass dates during the 2013 growing season. The increase in MAE seen here is likely associated with evaluating over multiple years with varying climatic conditions and vineyard management decisions, and the extension of analysis to year-round in the current study (Semmens et al. 2016 was limited to the growing season only). Modeled LE indicates underestimation when compared to closed observed LE estimates at site 1 , yielding a negative MBE of $-0.46 \mathrm{MJ} \mathrm{m}^{-2} \mathrm{~d}^{-1}$ (Table 1). The negative bias is most prevalent at the highest values associated with peak growing season, and is not present at site 2 or in comparison with the unclosed LE measurements.

Table 1. Statistical measures of flux retrieval performance on Landsat dates and daily estimates from the fused timeseries (Fusion) at sites 1, 2 and combination of sites 1 and 2 at 24-h, daily (fusion) and weekly time steps.

\begin{tabular}{|c|c|c|c|c|c|c|c|c|c|c|}
\hline \multirow{2}{*}{ Site } & Variable & Rs & $\mathrm{Rn}$ & $\mathrm{G}$ & $\mathrm{H}$ & LE & LE closed & ET (Landsat) & ET (Fusion) & ET (Fusion) \\
\hline & Unit & $M J m^{-2} d^{-1}$ & $M J m^{-2} d^{-1}$ & $M J m^{-2} d^{-1}$ & $M J m^{-2} d^{-1}$ & $M J m^{-2} d^{-1}$ & $M J m^{-2} d^{-1}$ & $m m / d a y$ & $m m / d a y$ & $\mathrm{~mm} /$ week \\
\hline \multirow{8}{*}{1} & $\mathrm{n}$ & 103 & 102 & 96 & 78 & 67 & 61 & 55 & 700 & 55 \\
\hline & meanO & 23.34 & 14.00 & 1.55 & 3.68 & 7.74 & 9.96 & 4.16 & 3.55 & 26.74 \\
\hline & $\mathrm{MBE}$ & 0.79 & -0.01 & -0.13 & 0.43 & 1.58 & -0.46 & -0.12 & -0.02 & -0.59 \\
\hline & RMSE & 2.49 & 1.95 & 0.92 & 1.92 & 2.44 & 2.13 & 0.79 & 0.80 & 3.91 \\
\hline & Slope & 1.07 & 0.96 & 0.08 & 0.19 & 0.67 & 0.62 & 0.67 & 0.74 & 0.70 \\
\hline & MAE & 1.62 & 1.13 & 0.70 & 1.43 & 2.05 & 1.69 & 0.60 & 0.62 & 3.06 \\
\hline & $\mathrm{R} 2$ & 0.89 & 0.82 & 0.05 & 0.04 & 0.80 & 0.80 & 0.81 & 0.78 & 0.80 \\
\hline & $\%$ Error & 7 & 8 & 45 & 39 & 27 & 17 & 15 & 18 & 11 \\
\hline \multirow{8}{*}{2} & $\mathrm{n}$ & 98 & 95 & 95 & 72 & 65 & 63 & 56 & 710 & 49 \\
\hline & meanO & 23.44 & 14.36 & 1.59 & 4.74 & 7.16 & 9.38 & 3.71 & 3.35 & 26.74 \\
\hline & MBE & 0.59 & -0.44 & -0.44 & 0.19 & 2.38 & 0.17 & 0.23 & 0.14 & 0.81 \\
\hline & RMSE & 2.47 & 2.02 & 0.77 & 1.54 & 2.93 & 1.73 & 0.73 & 0.74 & 4.07 \\
\hline & Slope & 1.10 & 1.01 & 0.10 & 0.46 & 0.68 & 0.64 & 0.76 & 0.87 & 0.76 \\
\hline & MAE & 1.55 & 1.10 & 0.57 & 1.27 & 2.48 & 1.36 & 0.57 & 0.57 & 3.17 \\
\hline & $\mathrm{R} 2$ & 0.89 & 0.81 & 0.03 & 0.21 & 0.56 & 0.63 & 0.69 & 0.73 & 0.74 \\
\hline & $\%$ Error & 7 & 8 & 36 & 27 & 35 & 14 & 15 & 17 & 12 \\
\hline \multirow{8}{*}{ Combined } & $\mathrm{n}$ & 201 & 197 & 191 & 150 & 132 & 124 & 111 & 1410 & 104 \\
\hline & meanO & 23.39 & 14.18 & 1.57 & 4.21 & 7.45 & 9.67 & 3.94 & 3.45 & 26.74 \\
\hline & MBE & 0.69 & -0.22 & -0.29 & 0.31 & 1.98 & -0.15 & 0.05 & 0.06 & 0.07 \\
\hline & RMSE & 2.41 & 3.09 & 0.94 & 2.05 & 2.57 & 1.92 & 0.76 & 0.77 & 3.98 \\
\hline & Slope & 1.08 & 0.92 & 0.09 & 0.27 & 0.61 & 0.65 & 0.69 & 0.79 & 0.72 \\
\hline & MAE & 1.58 & 1.12 & 0.63 & 1.35 & 2.27 & 1.52 & 0.58 & 0.59 & 3.11 \\
\hline & $\mathrm{R} 2$ & 0.89 & 0.77 & 0.01 & 0.08 & 0.67 & 0.72 & 0.74 & 0.75 & 0.77 \\
\hline & $\%$ Error & 7 & 8 & 40 & 32 & 30 & 16 & 15 & 17 & 12 \\
\hline
\end{tabular}


Rs, daytime solar radation; Rn, daytime integrated net radiation; G, daytime integrated soil flux; H, daytime integrated sensible heat; LE, daytime integrated latent heat; ET, daytime evapotranspiration on Landsat dates in $\mathrm{mm} \mathrm{d}^{-1}$; ET(Fusion), daily ET from 2013 to 2016 ; n, number of observations; meanO, mean measured flux; MAE, mean absolute error between the modeled and measured quantities; RMSE, root mean square error; \%error, percent error; MBE, mean bias error.

\section{Evaluation of daily ET from fused timeseries}

Scatter plots and associated timeseries of modeled 24-hr ET from the fused daily timeseries and daily fluxes observed at tower sites 1 and 2 between April 16, 2013 and October 19, 2016 are shown in Figures 3 and 4, respectively. Daily ET estimates from the fused remote sensing product follow the same general trend as the direct retrievals on Landsat overpass dates (Fig. 3). MAE for the full daily time series (closed) are $0.6 \mathrm{~mm} \mathrm{~d}^{-1}$ for both sites, comparable to the 0.7 $\mathrm{mm} \mathrm{d}^{-1}$ errors reported by Semmens et al (2016) for the 2013 growing season in isolation. Relative errors for both sites combined are $17 \%$ and $12 \%$ at daily and weekly time steps - the latter being more relevant for weekly irrigation scheduling.
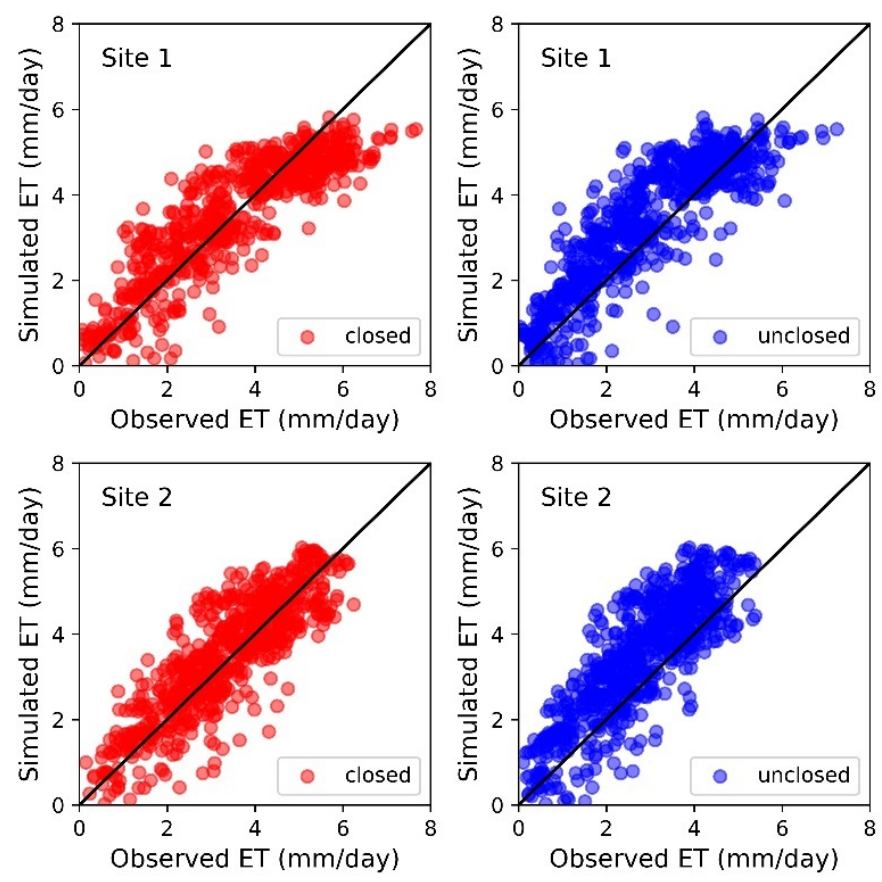

Figure 3. Scatterplots of modeled vs. observed closed (left panels) and unclosed (right panels) 24-h ET over the full simulation period from the fused timeseries for sites 1 (top panels) and 2 (bottom panels).

On both Landsat overpass dates (Fig 2) and in the full daily timeseries from the data fusion methodology (Fig 3), the modeled LE and ET underestimates the closed observed fluxes at site 1 at the very highest values. As seen in Fig. 4, these periods of underestimation occur between approximately mid-June and mid-August for each year and most notably for years 2013 and 2016. In both cases, the closure corrections using the residual method are relatively large, and the modeled ET is typically bracketed between closed and unclosed observed values. Such discrepancies are not observed at site 2 .

These large mid-season closure corrections and enhanced model-measurement discrepancies are likely related to advective conditions. In semiarid or arid regions, horizontal advection of hot, 
dry air, heated by the surrounding landscape, can significantly increase the localized evaporative demand over an irrigated field, driving large latent heat fluxes. In such cases, the additional energy required for evaporation is extracted from the surface itself, resulting in negative sensible heat and an increase in closure errors (Alfieri et al. 2012). A cursory analysis of the observed sensible heat fluxes at sites 1 and 2 revealed signatures of advection during the periods of lower closure, suggesting the RE method may be overestimating the real evaporative flux during those intervals. Furthermore, the tower footprint may be impacted under advective conditions, effectively sampling surface conditions further upwind. Anderson et al. (2018) found that peak observed flux estimates are better correlated with model fluxes extracted over a more central region of the vineyard that has more vigorous vine growth and yield production. Moreover, the assumption of self-preservation to upscale instantaneous flux retrieved at the satellite overpass time to daily totals depreciates under advective conditions (Crago 1996; Tang et al., 2013). Ongoing work is addressing both modeling and observational issues under the specific condition of strong mid-season advection.
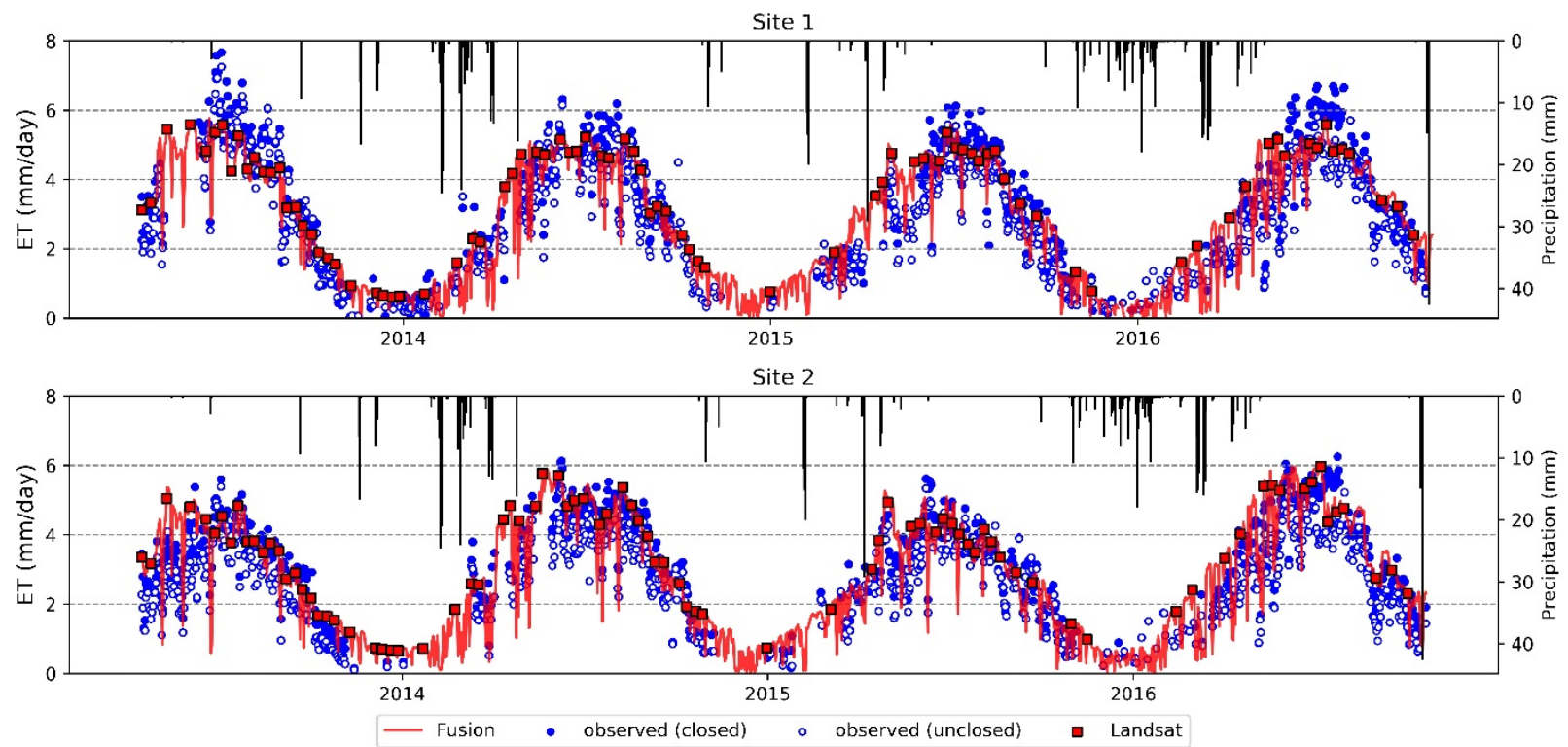

Figure 4. Time series of observed closed 24-h daily ET (blue dots), observed unclosed 24-h daily ET (white dots), 24-h daily ET retrievals on Landsat dates (red squares) and 24-h daily ET retrievals from the fused timeseries (red line) for site 1 (top panel) and site 2 (bottom panel). Daily precipitation measured at each site is indicated by the black vertical bars.

\section{Within-field variability in water use}

Routine remote sensing of daily ET at 30-m resolution will facilitate identification of areas of uneven ET/stress within vineyards due to variations in soil texture and composition and other environmental or anthropogenic factors. Figure 5 shows the variability in daily ET across both the northern and southern vineyards (sites 1 and 2) during the entire period of investigation. Spatial variability in ET increases during the growing season, with maximum variation occurring in July, then decreasing to a near-homogeneous distribution during the winter season. The northern vineyard exhibits a higher degree of spatial variability in ET, both in standard deviation and range, when compared to the southern vineyard. In the northern vineyard, the ET observed at the flux tower persistently lies near the upper bounds in standard deviation and range during the growing season. In general, at site 2, the flux tower samples are near the spatial mean of the 
remotely sensed distribution (Fig. 5). Overall, modeled spatial mean estimates of ET over the northern and southern vineyard are similar, with the only discrepancy found during the late growing season of 2013 and 2015, where values over the southern vineyard are slightly lower than in the northern vineyard (Fig. 5, bottom panel).

The analyses in Fig. 5 highlight the challenges in using isolated in-situ measurements to infer field-scale states and fluxes. As noted by Semmens et al. (2016), the northern field has large variability in soil texture, with the northwestern corner of the northern vineyard containing a silt/gravelly loam, resulting in poor to moderate water storage capacities and subsequently lower ET rates than observed in other parts of both fields, dominated by a Kimball silt loam. As a result, the tower footprint in site 1 captures conditions that are not always representative of the field as a whole. This is consistent with analyses presented by Anderson et al. (2018), who investigated spatial variability in correlations between the observed fluxes and modeled ET timeseries extracted in a moving window sampling a 600x600 m area around the Lodi tower sites, as a metric of tower representivity. They found that on average over two full annual cycles, tower fluxes at site 1 were best correlated with modeled ET to the southwest of the tower location, shifting to the vineyard center when the analysis was limited to the peak of the growing seasons. The southern vineyard showed less spatial variability in terms of tower-model agreement.
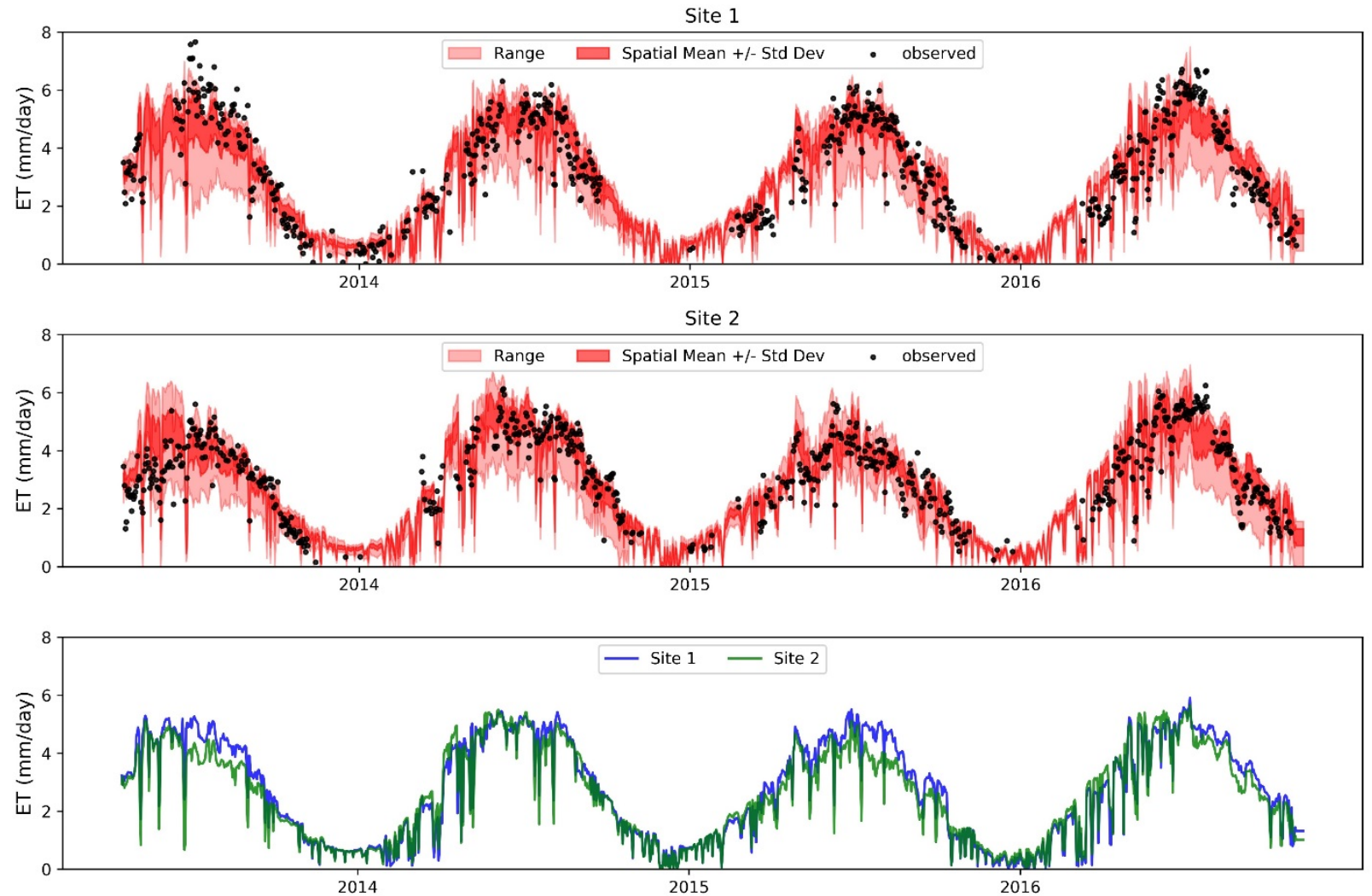

Figure 5. Time series of observed ET (black dots), spatial mean modeled ET with plus and minus standard deviation (dark red) and spatial range (maximum and minimum) modeled ET (light red) for the northern vineyard (top panel) and southern vineyard (middle panel). Also included is the time series of modeled spatial mean ET for both vineyards (bottom panel). 


\section{Local variability in water use}

Along with field ET estimates, spatial maps of ET over the local landscape can provide valuable context for irrigation decision makers. Vineyard managers often operate multiple vineyards, potentially with different varietals and irrigation management strategies. There may also be value in understanding irrigation and water use patterns in neighboring fields. As an example, maps of monthly ET over a roughly $3 \mathrm{~km}$ by $3 \mathrm{~km}$ box including the GRAPEX study area, with the northern and southern vineyards near the center, are presented in Figure 6. Over this 4-year period, some consistent seasonal patterns in water use are apparent. Beginning in March, localized ET enhancements in irrigated fields begin to emerge. Irrigation in the GRAPEX vineyards begins in early June and ends in early- to mid-October. Remnant evaporation of late season irrigation can be seen in these vineyards in October for each year.

Although seasonal patterns remain relatively consistent from year to year, some discernable changes in local water use can be seen over the four-year period, particularly during the growing season. These changes are largely related to changes in land-use. For example, evidence of irrigation in a new vineyard established just west of site one in early 2014 is manifested as a substantial increase between 2013 and 2014 and persisting through the 2015-2016 growing seasons (outlined in black; Fig. 6). In addition, ET in the field due south of the southern vineyard (also outlined in Fig. 6) decreases notably in 2016 due to fallowing of an alfalfa field after May of that year, possibly the result of grower response to long-term drought conditions and resulting water limitations (Anderson et al., 2018). Spatial weekly or monthly maps of local ET at this scale provide vineyard managers with information about local land- and water-use changes, which may have bearing on in-field decision making and long-term strategic planning.

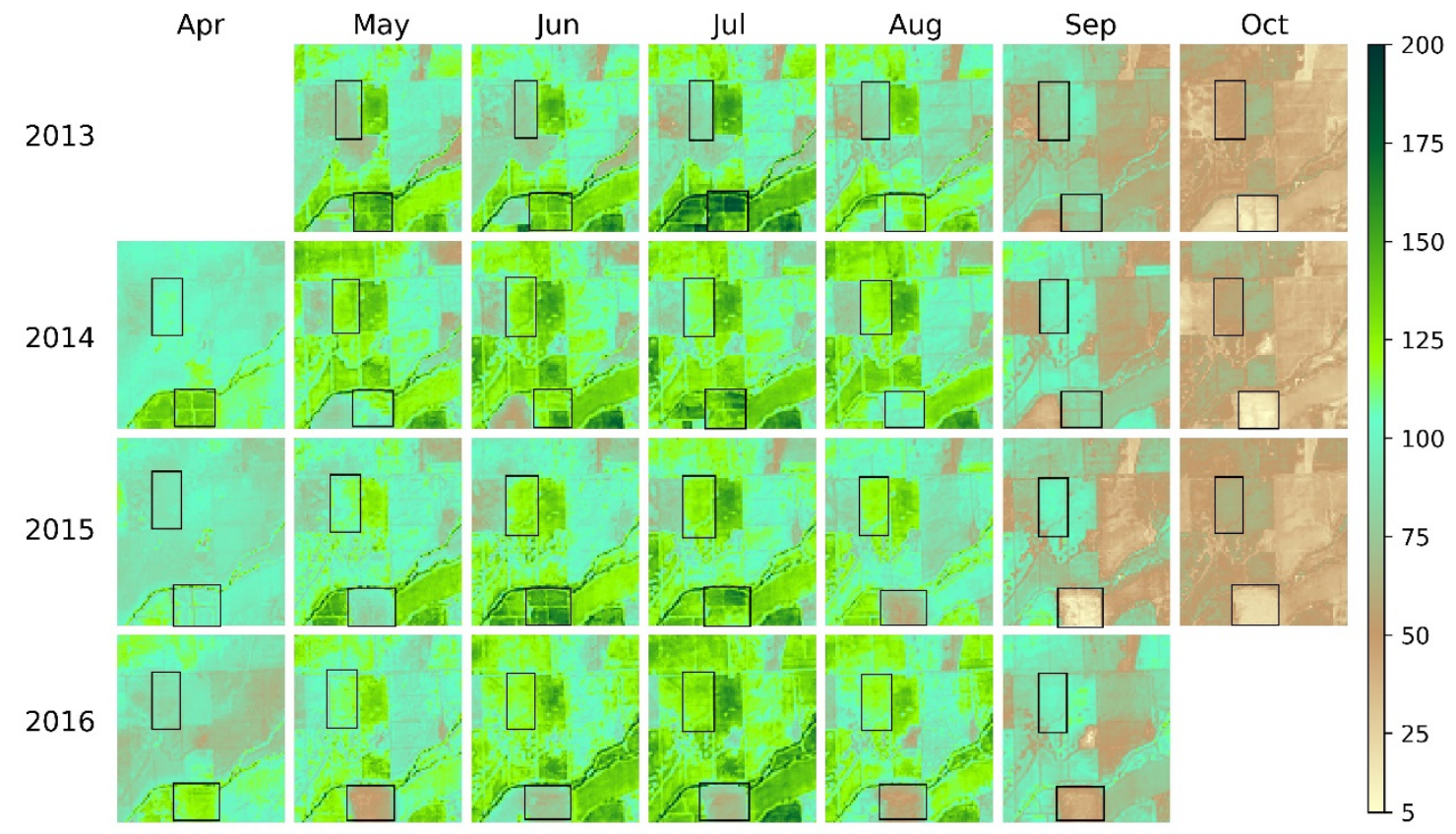

Figure 6. Spatial time series (monthly) of ET $\left(\mathrm{mm} \mathrm{month}^{-1}\right)$ over a $3 \times 3 \mathrm{~km}$ area including the northern and southern vineyards instrumented for GRAPEX. Boxes demarcate the new vineyard established west of the northern vineyard and an alfalfa field left fallow following the 2015 growing season. 


\section{Use of remote sensing for monitoring vineyard water stress and managing irrigation}

This study investigates two remote sensing metrics that may be useful in vineyard irrigation management are total daily or weekly ET (relating to consumptive water use - water extracted from the soil profile requiring replacement), and the moisture stress factor $f_{\text {RET. }}$ Grape development is strongly dependent on vine water status, and strategies for optimizing wine grape quality are often associated with imposing some degree of water stress in the vine during specific phenological periods. This degree of stress is achieved through regulated deficit irrigation (RDI), estimated as a fraction of the full crop potential water use. Current operational practices utilize the Food and Agricultural Organization (FAO-56) model to estimate crop potential water use based on the reference ET and a crop coefficient (commonly referred to as $\mathrm{K}_{\mathrm{c}}$ ) describing the average ratio of actual-to-reference ET for different crops under well-watered conditions. The $f_{\text {RET }}$ quantity used in the regional-scale ESI agricultural drought indicator effectively represents a dynamic crop coefficient, diagnostically retrieved via thermal remote sensing and responding to daily changes in localized crop stress and development.

To illustrate the utility of a daily Landsat-scale $f_{\text {RET }}$ product for stress detection, Fig. 7 compares modeled values to observations derived from tower measurements of actual and reference ET. Reference ET is calculated in both cases using the Penman-Monteith formulation, as described in the FAO standard for a short grass (Allen et al. 1998), computed using tower data in the observed case and using regional meteorological data (NCEP CFSR data set; Dee et al. 2013) for the modeled case. Observed Actual ET is taken as the observed 24-hr daily closed flux tower measurement, while the modeled ET values are extracted from the fused timeseries at the tower sites. Also shown are rainfall and irrigation amounts measured in-field, the latter only available for the 2015 and 2016 growing seasons (see zoom-in in Fig. 7; bottom panel).

In general, the fused $\mathrm{f}_{\mathrm{RET}}$ timeseries reproduces observed seasonal patterns inferred from the tower observations with good fidelity. Small mid-season biases are observed in 2013 and 2015 at site 1, relating to localized advective issues discussed earlier. This bias is non-existent at site 2, where both modeled and observed $\mathrm{f}_{\text {RET }}$ estimates are similar throughout the study period. Both modeled and measured $f_{\text {RET }}$ indicate lower peak season $f_{\text {RET }}$ values at site 2 during 2013 and 2015 when compared to 2014 and 2015, consistent with the cyclical annual ET patterns in Fig. 4. 


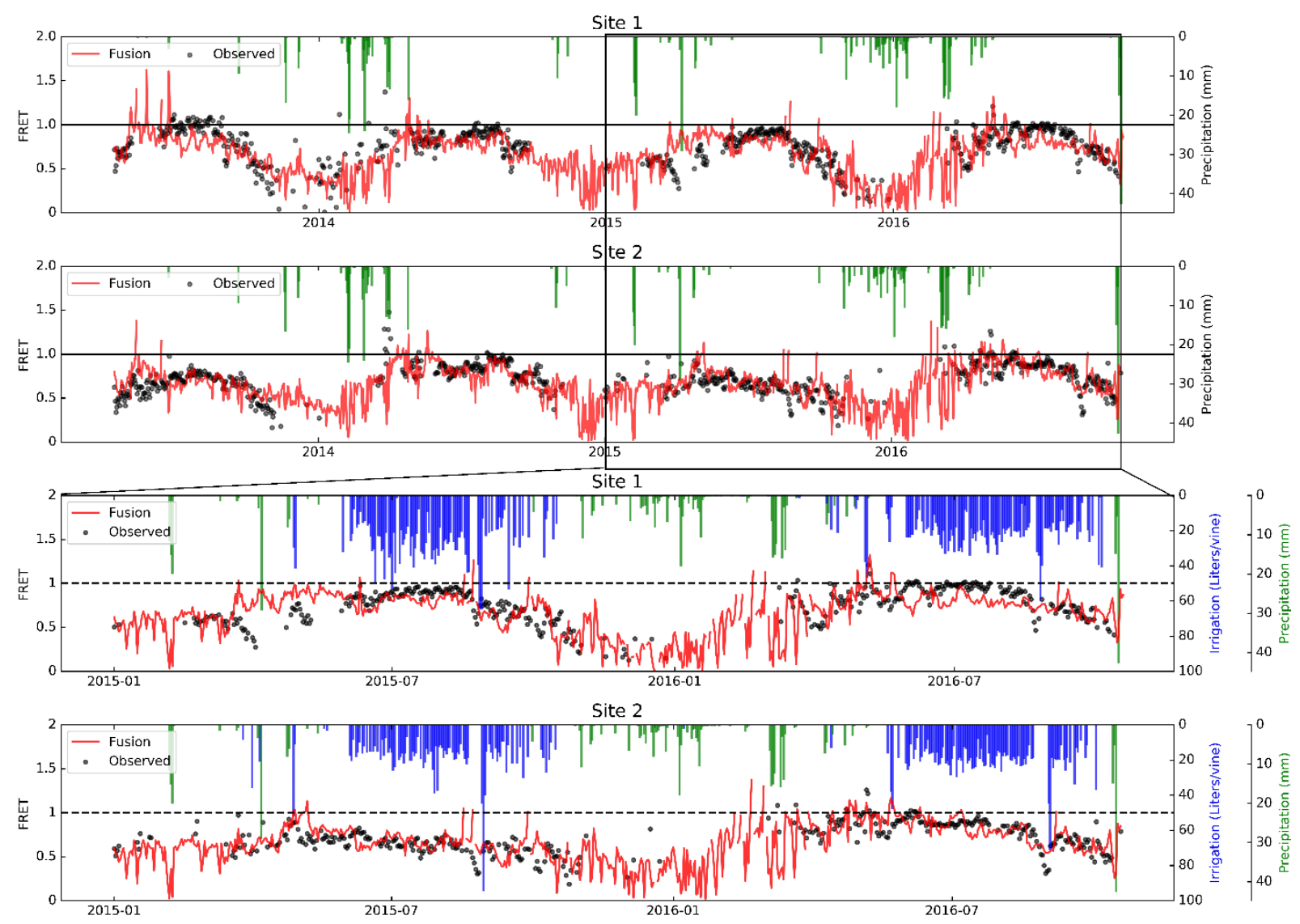

Figure 7. Timeseries of $\mathrm{f}_{\mathrm{RET}}$ derived from closed observations (black dots) and the fused ET timeseries (red line) derived from point estimates for site 1 (top panel) and site 2 (second from top panel) during the entire study period, along with daily rainfall (green bars). Also included is an enhanced view of 2015 and 2016 (bottom two panels), which includes daily irrigation totals (blue bars) presented in Liters/vine.

During 2015-2016, when detailed irrigation information is available (Fig. 7; bottom panels), we can closely investigate relationships between $f_{\text {RET }}$ and daily irrigation amounts, expressed in in units of liters per vine. Observed and modeled $f_{\text {RET }}$ fluctuate rapidly during the non-growing season when canopy cover is sparse and no irrigation is occurring, reflecting the relative volatility in the soil evaporation and cover crop transpiration contributions that dominate total ET during this period. Once irrigation commences, $\mathrm{f}_{\mathrm{RET}}$ remains more stable and near target levels (0.8-1.0) until after harvest. Note that irrigation is suspended each year briefly (5-7 days) around harvest near the end of August, then resumed post-harvest until early-to-mid October to maintain the canopy. After harvest, both observed and modeled $f_{R E T}$ decay as the vines senesce. 


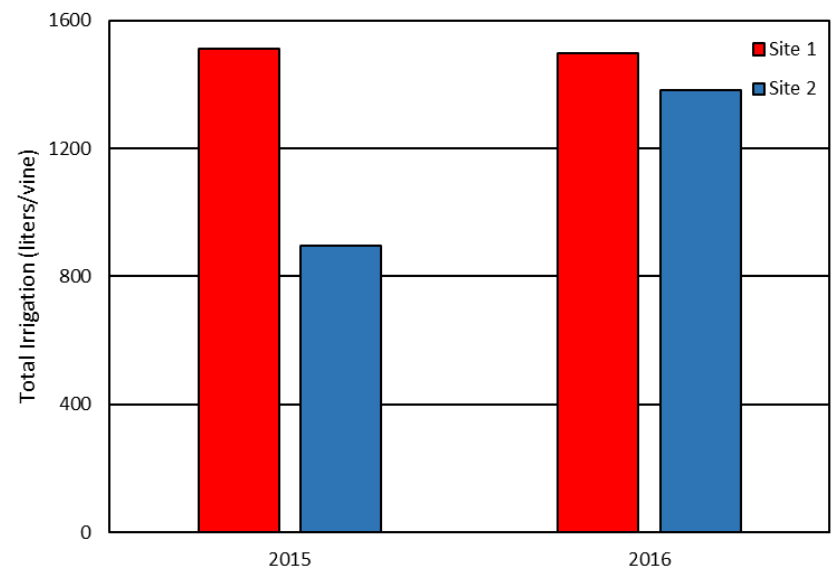

Figure 8. Total irrigation applied (liters/vine) over 2015 and 2016 growing seasons in the site 1 and 2 vineyards.

During the growing season, remotely sensed $f_{\text {RET }}$ values in both vineyards show response to seasonal irrigation amounts. In 2015 , site 2 received about $60 \%$ of the daily irrigation amounts applied to site 1, while in 2016 the irrigation strategy was more uniform, with site 2 at $92 \%$ of site 1 (Fig. 8). Irrigation at site 1 varied by only $1 \%$ between the two years, while site 2 increased by $54 \%$ in 2016 . These variations in irrigation management are reflected in the average remote sensing f $f_{\text {RET }}$ retrieved during the irrigation season (pre-harvest), around 0.7 for site 2 in 2013 and 0.8 in all other cases.

Regional differences in applied irrigation can be seen in the spatiotemporal patterns of monthly average 30-m fused $f_{\text {RET }}$ (Fig. 9). After irrigation is initiated (beginning of June), there is a clear distinction in $f_{\text {RET }}$ between the vineyards in 2013 and 2015, but less difference in 2014/2016, reflecting differentials in irrigation amounts applied to the two fields (Fig. 8). While the relative patterns in monthly $f_{\text {RET }}$ are similar to those in total ET shown in Fig. 6, normalization by reference ET serves to reduce dependence on the seasonal evaporative demand curve, focusing more specifically on variations in moisture conditions driving the evaporative fluxes. These maps also provide information on irrigation initiation in surrounding fields. The $f_{\text {RET }}$ maps for April in Fig. 9 emphasize wetter springtime conditions in 2014, as well as early initiation of irrigation in the fields to the southwest in 2014 and 2016.

Anomalies in monthly $f_{\text {RET }}$, computed as the difference with respect to the long-term (here 4year) mean $f_{\text {RET }}$ map for each month are useful for highlighting regions anomalous moisture stress and water use in real time (Fig. 9; bottom panel). In April, May and June of 2015 we see pronounced negative anomalies in the southern vineyard, which are also present, albeit to a smaller degree, during the remainder of the growing season. These anomalies indicate stress in the vineyard likely correlated to the lesser amount of irrigation applied during the 2015 growing season and subsequent reduced yield as discussed earlier. Regional precipitation in October of 2015 may have helped to reduce the $f_{\text {RET }}$ anomaly signal from September to October. In some cases, reflect changes in land-use and water management rather than stress. In 2013 we see strong negative anomalies in the areas where new vineyards were established in 2014, to the west and south of site 1 . The alfalfa field fallowed in May of 2016 is clearly apparent. Drier than normal conditions are detected for the month of September in 2015 over the region just east of the GRAPEX vineyard sites. This may be related to management/harvest decisions in response to 
the multi-year drought conditions that prevailed in California during the study period, leading to increasing pressure on water availability for irrigation. Spatial $f_{R E T}$ and $f_{R E T}$ anomaly products such as these prove capable of monitoring dynamic crop coefficients and highlighting changing conditions, not only within a field of interest, but also on a regional scale.

Figure 9. Spatiotemporal time series (monthly) of $f_{\text {RET }}$ (top panel) and $f_{\text {RET }}$ anomaly (bottom panel) over a 3 x $3 \mathrm{~km}$ area including the northern and southern vineyards instrumented for GRAPEX.

\section{Relationships between vineyard water use, stress and yields}

The ultimate objective in this study is to motivate use of remote sensing toward meeting the dual goals of reducing water use while improving yield and grape quality. Figure 10 provides a more detailed view of annual water use patterns and its relation to grape yield over the two GRAPEX vineyards, showing cumulative ET over the peak growing season (May-August) in the top panel and grape yield (tons ha ${ }^{-1}$ ) in the bottom panel.

The cumulative ET maps show distinct spatial structure. Two low ET features in the southcentral portion of the northern vineyard are associated with vernal pools - small areas having no vines and no irrigation because of protection by state and federal law from any cultivation activities (see also Semmens et al., 2016). These ephemeral wetlands emerge after rainfall events, but during most of the growing season are dry leading to persistently low values of seasonal ET. There is also the persistence in lower ET in the northwest corner of the northern (site 1) vineyard, which is associated with poor vine growth due to soil properties. This corner of the field has silt loam and gravelly loam soils characteristic of poor to moderate water storage capacity (Semmens et al. 2016), while the center of the northern vineyard is Kimball silt loam and is characteristic of more vigorous vine growth. The latter is characterized by high rates of seasonal consumptive water use. The increased water use associated with the new vineyards established to the west and south of the north vineyard after the 2013 growing season can also be observed in Fig. 10. Total ET during the peak growing season increases from roughly $300 \mathrm{~mm}$ $\mathrm{yr}^{-1}$ during 2013 to $520-550 \mathrm{~mm} \mathrm{yr}^{-1}$ during 2014 over this region due to irrigation applied to help establish the recently planted vines.

Much of this spatial structure in seasonal ET is well correlated in patterns in yield maps, collected over the GRAPEX fields using GPS-enabled sensors on the harvesters. The cyclical ET dynamics in the southern vineyard (site 2), with relatively high cumulative water use in 2014 and 2016, reflects grower decisions in irrigation management in this field. In the northern vineyard (site 1), the cumulative water use is lower in 2013 than in 2014-2016. Similar spatial and temporal patterns are seen in the reported total yield for each site (Fig. 10). Specifically, total yield for 2015 in the southern vineyard is considerably lower than in the northern vineyard, while also being lower than both the north and south vineyards in 2016, corresponding to trends in both $f_{\text {RET }}$ and irrigation. This instance of decreased yield may be the result of increased stress imposed over the southern vineyard (shown in $f_{\text {RET }}$ ) through restricted irrigation during the 2015 growing season (Fig. 8). Despite the lack of irrigation data during the 2013 and 2014 growing seasons, trends in $f_{\text {RET }}$ correspond to yield totals - most notably in the southern vineyard - where $f_{\text {RET }}$ 
values are lowest during the 2013 and 2015 growing season (Fig. 7). In the northern vineyard, yields are lowest in 2013 - the year of lowest cumulative water use.

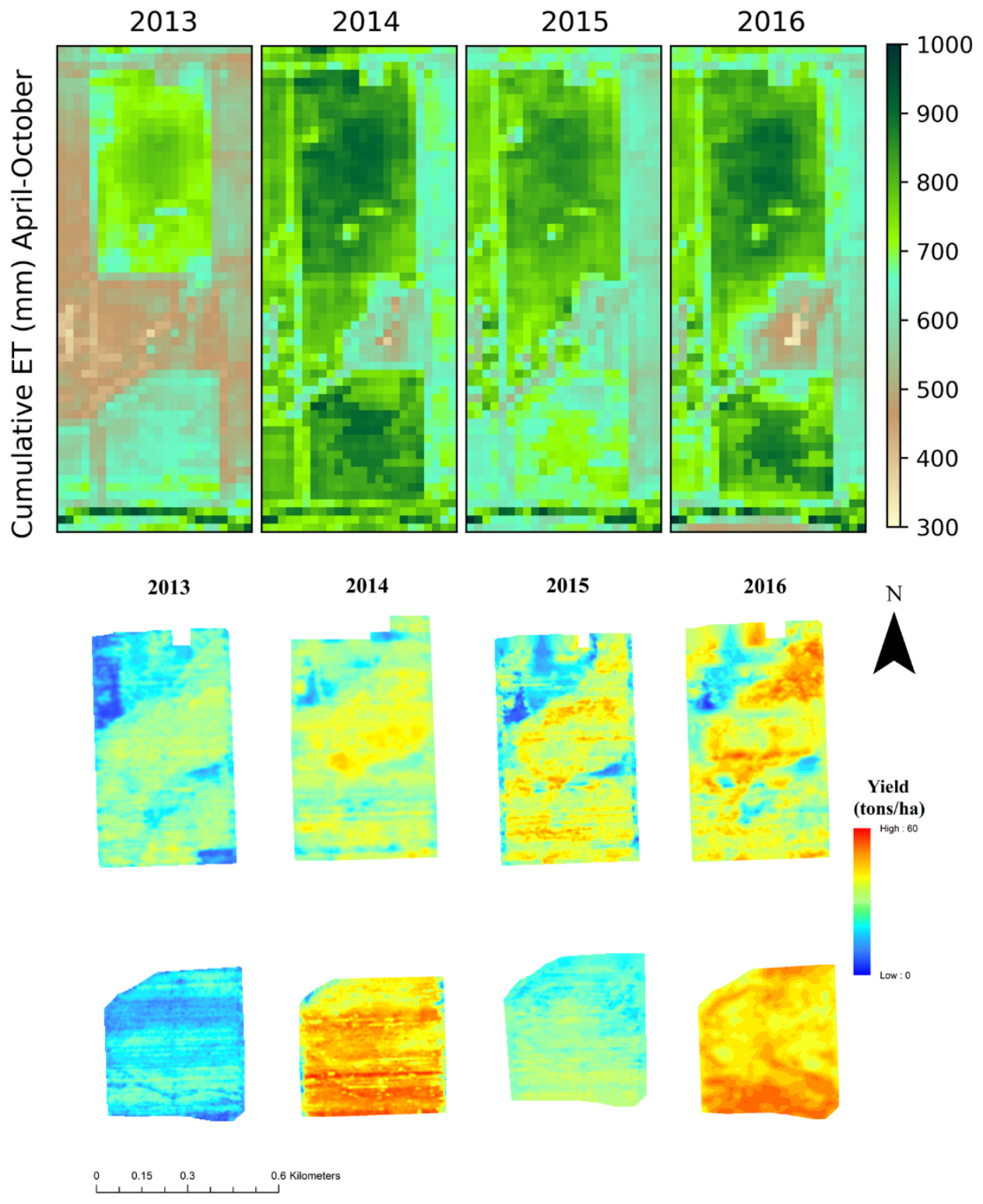

Figure 10. Cumulative peak growing season (May-August) ET (mm) (top) and total yield in tons/ha (bottom) over the northern and southern vineyards for years 2013, 2014, 2015 and 2016.

The spatial distribution of cumulative growing season ET (Fig. 10) also roughly follows that of yield, with larger values of both reported near the center of the northern vineyard for all years. As noted above, spatial heterogeneity in the northern vineyard is associated with soil texture discontinuities and vine growth vigor. Low yields in the NW corner are spatially correlated with lower seasonal ET, while the center of the northern vineyard has persistently the highest yields and seasonal water use. A similar spatial correlation to yield is presented in Sun et al. (2017), where the biophysical parameters NDVI and LAI show a similar spatial correlation to grape yield over the same vineyards during 2013 and 2014, although the relationship is more variable from year to year. Ongoing work looks to expand upon research done in Sun et al. (2017) by 
examining the joint use of remotely sensed $\mathrm{LAI} / \mathrm{ET} / \mathrm{f}_{\mathrm{RET}}$ signals to predict yield variations over a larger dataset of vineyards and over an extended period.

\section{Summary and Conclusions}

A remote sensing approach for mapping daily ET at 30-m spatial resolution is evaluated over two vineyard sites in central California for the 2013-2016 growing seasons to investigate the utility for irrigation management. Mean absolute errors in comparison with in-situ eddy covariance measurements of daily ET were $0.6 \mathrm{~mm} \mathrm{~d}-1$, or about $17 \%$ of the mean observed value. Errors reduced to $15 \%$ at the weekly timesteps relevant to irrigation management. In comparison with eddy covariance fluxes forced for closure, the model tended to underestimate closed observations in the northern vineyard site during highly advective periods for the peak growing season in 2013 and 2016. During this period, the closure errors in the observations were exacerbated, and therefore the tendency to underestimate is partly attributed to issues with the flux measurements and closure technique and not the model alone. Model errors may be associated with the self-preservation assumptions in the daily upscaling technique, which may be less reliable under advective conditions.

Monthly total ET maps and the spatial variation time series demonstrate strong seasonal water use variability, both within the vineyards themselves and over the surrounding landscape. In the northern vineyard, the flux tower location was not representative of the field-scale mean properties in some years, highlighting challenges in managing irrigation decisions based on point-scale measurements. Timeseries of monthly ET maps revealed consistent seasonal dynamics year-to-year in water use patterns over the GRAPEX study area, but with some notable variations due to changes in land use and water management. Within vineyard spatial variability of cumulative growing season ET and actual-to-reference ET $\left(f_{\mathrm{RET}}\right)$ correlate well with yield totals, demonstrating the impact of potential stress on future yield prospects. Maps of fRET demonstrate utility for monitoring how consistently target values (between 0.8 and 1.0 in this case) are achieved for a given field, and could be useful for adaptive management of irrigation applications in real time. Maps of $f_{R E T}$ anomalies highlight emerging areas of anomalous water use or stress that could alert needs for modified management or further investigation.

The modeling approach described here can provide detailed and robust information on daily to seasonal crop water use and stress. Applied operationally, this ET mapping framework can be of great utility to irrigation managers, both for individual vineyard assessment and larger regional application. Improved spatial and temporal monitoring will improve water allocation and conservation efforts through an ability to identify areas of uneven productivity/stress due to variations in soil texture and composition and other environmental or anthropogenic factors. This will allow vineyard managers to identify areas in their blocks with water, nutrient or other environmental stressors as well as malfunctions in the irrigation systems. Moreover, with reliable daily 30-m ET, growers and irrigation managers have the potential to make use of variable rate irrigation systems that can apply appropriate amounts of irrigated water and nutrients to specific areas within a vineyard to achieve more uniform grape quality and yield goals. There is also potential to incorporate very fine resolution aerial imagery from UAVs or manned aircraft for identifying individual or groups of vines requiring intervention at critical periods during vine and 
grape development stages when stress conditions are detected at the coarser $30 \mathrm{~m}$ satellite resolution.

In ongoing work, this fusion-based ET mapping system is being applied over different vine varieties and climate regions within California as part of the continued effort of the GRAPEX project (Kustas et al., 2018). The ability to reliably monitor evaporative water loss and crop conditions at both the field and regional scale is imperative to viticulture and agricultural production systems alike, especially in regions with competing demands for limited water resources.

\section{Acknowledgements}

Authors would like to thank the staff of Viticulture, Chemistry and Enology Division of E\&J Gallo Winery for the collection and processing of field data and insight to local irrigation practices. Authors would also like to thank the Borden vineyard staff for logistical support of GRAPEX field and research activities. USDA is an equal opportunity provider and employer.

\section{Conflict of Interest}

Authors report no conflicts of interest in the material presented in this study.

\section{References}

Alfieri JG, Kustas WP, Prueger JH, Hipps LE, Evett SR, Basara JB, Neale CMU, French AN, Colaizzi PD, Agam N, Cosh MH, Chavez JL, Howell TA (2012) On the discrepancy between eddy covariance and lysimetry-based turbulent flux measurements under strongly advective conditions. Advances in Water Resources 50:62-78. doi: 10.1016/j.advwatres.2012.07.008

Alfieri JG, Kustas WP, Prueger JH, McKee LG, Hipps LE, Gao F (this issue) A multi-year intercomparison of micrometeorological observations at adjacent vineyards in California's central valley during GRAPEX. Irrig Sci

Allen RG, Pereira LS, Raes D, Smith M (1998) Crop evapotranspiration. Guidelines for computing crop water requirements. FAO Irrigation and Drainage Paper 56. FAO, Rome, Italy

Allen RG, Tasumi M, Trezza R, (2007) Satellite-based energy balance for mapping evapotranspiration with internalized calibration (METRIC) - Model. J Irrig Drain Eng 133:380394. doi: 10.1061/(ASCE)0733-9437.

Anderson MC, Norman JM, Diak GR, Kustas WP, Mecikalski JR (1997) A two-source timeintegrated model for estimating surface fluxes using thermal infrared remote sensing. Remote Sens Environ 60:195-216. doi: 10.1016/S0034-4257(96)00215-5.

Anderson MC, Norman JM, Mecikalski JR, Torn RD, Kustas WP, Basara JB (2004) A multiscale remote sensing model for disaggregating regional fluxes to micrometeorological scales. $\mathrm{J}$ Hydrometeorol 5:343-363. doi: 10.1175/1525-7541(2004)005<0343:AMRSMF>2.0.CO;2 
Anderson MC, Norman JM, Kustas WP, Li F, Prueger JH, Mechikalski JR (2007a) A climatological study of evapotranspiration and moisture stress across the continental United States: I. Model formulation. J Geophys Res 112 doi: 10.1029/2006JD007506.

Anderson MC, Norman JM, Mecikalski JR, Otkin PJ, Kustas WP (2007b) A climatological study of evapotranspiration and moisture stress across the continental United States: II. Surface moisture climatology. J Geophys Res 112 doi: 11110.11029/12006JD007507.

Anderson MC, Hain CR, Wardlow B, Mecikalski JR, Kustas WP (2011) Evaluation of drought indices beased on thermal remote sensing of evapotranspiration over the continental U.S. J Climate 24: 2025-2044. doi: 10.1175/2010JCLI3812.1

Anderson MC, Kustas WP, Alfieri JG, Gao F, Hain C, Prueger JH, ...Chavex JL (2012) Use of Landsat thermal imagery in monitoring evapotranspiration and managing water resources. Remote Sens Environ 122:50-65. doi: 10.1016/j.rse.2011.08.025

Anderson MC, Hain CR, Otkin JA, Zhan X, Mo KC, Svoboda M et al. (2013) An intercomparison of drought indicators based on thermal remote sensing and NLDAS-2 simulations with U.S. Drought Monitor classifications. J Hydrometeorol 14:1035-1056. doi: 10.1175/JHM-D-12-0140.1

Anderson MC, Gao F, Knipper KR, Hain CR, Dulaney W, Baldocchi D, Eichelmann E, Hemes K, Yang Y, Medellin-Azuara J, Kustas K (2018) Field-scale assessment of land and water use change over the California Delta using remote sensing. Remote Sens 10. doi: $10.3390 /$ rs 10060889 .

Azevedo PV, Soares JM, Silva V, Silva BB, Nascimento T (2008) Evapotranspiration of "Superior" grapevines under intermittent irrigation. Agric Water Manage 95:301-308. doi: 10.1016/j.agwat.2007.10.011

Basile B, Marsal J, Mata M, Vallverdú X, Bellvert J, Girona J (2011) Phenological sensitivity of Cabernet Sauvignon to water stress: vine physiology and berry composition. Am J Enol Vitic 62:452-461. doi: 10.5344/ajev.2011.11003

Bastiaanssen WGM, Menenti M, Feddes RA, Holtslag, AAM (1998) A remote sensing surface energy balance algorithm for land (SEBAL): 1. Formulation. J of Hydrol 212-213: 198-212. doi: 10.1016/S0022-1694(98)00253-4.

Bellvert J, Marsal J, Mata M, Girona J (2012) Identifying irrigation zones across a 7.5-ha 'Pinot noir' vineyard based on the variability of vine water status and multispectral images. Irrig Sci 30:499-509. doi: 10.1007/s00271-012-0380-y

Bellvert J, Marsal J, Girona J, Gonzalex-Dugo V, Fereres E, Ustin S, Zarco-Tejada PJ (2016) Airborne thermal imagery to detect the seasonal evolution of crop water satus in peach, nectarine and Saturn peach orchards. Remote Sens 8. doi: 10.3390/rs8010039. 
Berk A, Bernstein LS, Robertson DC (1989) MODTRAN: A moderate resolution model for LOWTRAN 7. GL-TR-89-0122. Bedford, MA: Air Force Geophysics Lab, 38.

Bramley RGV, Hamilton RP (2004) Understanding variability in winegrape production systems. 1 . Within vineyard variation in yield over several vintages. Aust J Grape Wine Res 10:32-45. doi: $10.1111 / \mathrm{j} .1755-0238.2004 . t b 00006 . x$

Bramley RGV, Oriffitt, APB, Hinze CJ, Pearse B, Hamilton RP (2005) Generating benefits from precision viticulture through selective harvesting. Stafford, JV ed. Precision agriculture '05. Proceedings of the $5^{\text {th }}$ European conference on precision agriculture; 9-12 June; Uppsala Sweden (Wageningen Academic Publishers: Wegeningen, The Netherlands) pp. 891-898.

California Department of Food and Agriculture \& USDA National Agricultural Statistics Service (2016) California Agricultural Statistics Review, 2015-2016. Access Date: Aug, 2017. Available online https://www.cdfa.ca.gov/statistics/PDFs/2016Report.pdf

California Department of Food and Agriculture \& USDA National Agricultural Statistics Service (2017). California grape acreage report 2016 crop. Access date: Aug 2017. Available on-line http://www.nass.usda.gov/Statistics_by_State/California/Publications/Grape_Acreage

Cammalleri C, Anderson MC, Gao F, Hain C, Kustas WP (2013) A data fusion approach for mapping daily evapotranspiration at field scale. Water Resour Res 49:4672-4686. doi: 10.1002/wrcr.20349

Cammalleri C, Anderson MC, Kustas WP (2014a) Upscaling of evapotranspiration fluxes from instantaneous to daytime scales for thermal remote sensing applications. Hydrol Earth Syst Sc 18:1885:1894. doi: 10.5194/hess-18-1885-2014

Cammalleri C, Anderson MC, Gao F, Hain CR, Kustas WP (2014b) Mapping daily evapotranspiration at field scales over rainfed and irrigated agricultural areas using remote sensing data fusion. Agric For Meteorol 186:1-11. doi: 10.1016/j.agrformet.2013.11.001

Cancela JJ, Fandino M, Rey BJ, Rosa R, Pereira LS (2012) Estimating transpiration and soil evaporation of vineyards from the fraction of ground cover and crop height - application to 'Albarino' vineyards of Galicia. Acta Horticulture (ISHS) 931:227-234. doi:

10.17660/ActaHortic.2012.931.25

Castellvi F, Snyder RL (2010) A new procedure based on surface renewal analysis to estimate sensible heat flux: a case study over grapevines. J Hydrometeorol 11:496-508. doi: 10.1175/2009JHM1151.1

Crago R (1996) Conservation and variability of the evaporative fraction during the daytime. J Hydrol 180:173-194. doi: 10.1016/0022-1694(95)02906-6 
Dee DP, Balmaseda M, Balsamo G, Engelen R, Simmons AJ, Thépaut JN (2013) Toward a consistent reanalysis of the climate system. Bull Am Meteorol Soc. 95(8):1235-1248. doi: 10.1175/BAMS-D-13-00043.1

Diak GR (2017) Investigations of improvements to an operational GOES-satellite-data-based insolation system using pyranometer data from the U.S. Climate Reference Network (USCRN). Remote Sens Environ 195, 79-95. doi: 10.1016/j.rse.2017.04.002.

French AN, Norman JM, Anderson MC (2003) A simple and fast atmospheric correction for spaceborne remote sensing of surface temperature. Remote Sens Environ 87:2-3.

Fry JA, Xian G, Jin S, Dewitz JA, Homer CG, Yang L, Barnes CA, Herold ND, Wickham JD (2011) Completion of the 2006 national land cover database for the conterminous United States. Photogramm Eng Remote Sens. 77(9):858-864.

Gao F, Masek J, Schwaller M, Hall F (2006) On the blending of the Landsat and MODIS surface reflectance: Predicting daily Landsat surface reflectance. IEEE Trans Geosci Remote Sens 44:2207-2218. doi: 10.1109/TGRS.2006.872081.

Gao F, Morisette JT, Wolfe RE, Ederer G, Pedelty J, Masuoka E, Myneni R, Tan B, Nightingale $\mathrm{J}$ (2008) An algorithm to produce temporally and spatially continuous MODIS-LAI time series. IEEE Geosci Remote Sens Lett. 5(1):60-64. doi: 10.1109/LGRS.2007.907971

Gao F, Kustas W, Anderson M (2012a) A data mining approach for sharpening thermal satellite imagery over land. Remote Sens 4:3287-3319. doi: 10.3390/rs4113287.

Gao F, Anderson MC, Kustas WP, Wang Y (2012b) Simple method for retrieving leaf area index from Landsat using MODIS leaf area index products as reference. J Appl Remote Sci. 6(1):063554. doi:10.1117/1JRS.6.063554

Girona J, Mata M, del Campo J, Arbonés A, Bartra E, Marsal J (2006) The use of midday leaf water potential for scheduling deficit irrigation in vineyards. Irrig Sci 24:115-127. doi: 10.1007/s00271-005-0015-7

Girona J, Marsal J, Mata M, del Campo J, Basile B (2009) Phenological sensitivity to berry growth and composition of Tempranillo grapevines (Vitis vinifera L.) to water stress. Aust J Grape Wine Res 15:268-277. doi: 10.1111/j.1755-0238.2009.00059.x

Hansen MC, DeFries RS, Townshend JRG, Sohlberg R (2000) Global land cover classification at $1 \mathrm{~km}$ spatial resolution using a classification tree approach. Int J Remote Sens 21:1331-1364.

Intrigliolo DS, Lakso AN, Piccioni RM (2009) Grapevine cv, 'Riesling' water use in the northeastern United States. Irrig Sci 27:253-262. doi: 10.1007/s00271-008-0140-1

Johnson RS, Williams LE, Ayars JE, Trout TJ (2005) Weighing lysimeters aid study of water relations in tree and vine crops. Calif Agric 59:133-136. doi: 10.1007/s00271-008-0124-1 
Jönsson P, Eklundh L (2004) TIMESAT - A program for analyzing time-series of satellite sensor data. Computers and Geosciences 30:833-845.

Kustas WP, Norman JM (1999) Evaluation of soil and vegetation heat flux predictions using a simple two-source model with radiometric temperatures for partial canopy cover. Agric For Meteorol 94:13-29. doi: 10.1016/SO168-1923(99)00005-2.

Kustas WP, Anderson MC, Alfieri JG, Knipper K, Torres-Rua A, Parry CK, Nieto H, Agam N, White A, Gao F, McKee L, Prueger JH, Hipps LE, Los S, Alsina M, Sanchez L, Sams B, Dokoozlian N, McKee M, Jones S, McElrone A, Heitman JL, Howard AM, Post K, Melton F, Hain C (2018) The Grape Remote sensing Atmospheric Profile and Evapotranspiration eXperiment (GRAPEX). B Am Meteorol Soc. 99:1791-1812.

Laszlo I, Ciren P, Liu H, Kondragunta S, Tarpley J, Goldberg M (2008) Remote sensing of aerosol and radiation from geostationary satellites. Adv Space Res 41: 1882-1893. doi: 10.1016/j.asr.2007.06.047.

McNaughton KG, Spriggs TW (1986) A mixed-layer model for regional evaporation. Bound Lay Meteorol 34: 243-262. doi: 10.1007/BF00122381.

Mecikalski JM, Diak GR, Anderson MC, Norman JM (1999) Estimating fluxes on continental scales using remotely-sensed data in an atmosphere-land exchange model. J Applied Meteorol. 38:1352-1369. doi: 10.1175/1520-0450(1999)038<1352:EFOCSU>2.0.CO;2.

Moran MS (2003) Thermal infrared measurements as an indicator of plant ecosystem health, in: Thermal Remote Sensing in Land Processes, edited by: Quattrochi DA and Luval J, Taylor and Francis 257-282.

Moratiel R, Martinez-Cob A (2012) Evapotranspiration of grapevine trained to a gable trellis system under netting and black plastic mulching. Irrig Sci 30:167-178. doi: 10.1007/s00271011-0275-3

Netzer Y, Yao C, Shenker M, Bravdo BA, Schwartz A (2009) Water use and the development of seasonal crop coefficients for Superior Seedless grapevines trained to an open-gable trellis system. Irrig Sci 25:161-170. doi: 10.1007/s00271-008-0124-1

Norma JM, Kustas WP, Humes KS (1995) A two-source approach for estimating soil and vegetation energy fluxes from observations of directional radiometric surface temperatures. Agric For Meteorol 77:263-293. doi: 10.1029/97WR00704.

Norman JM, Anderson MC, Kustas WP, French AN, Mecikalski J, Torn R, Tanner BCW (2003) Remote sensing of surface energy fluxes 101-m pixel resolutions. Water Resources Research 39. doi: 10.1029/2002WR001775. 
Ortega-Farias S, Poblete-Echeverria C, Brisson N, (2010) Parameterization of a two-layer model for estimating vineyard evapotranspiration using meteorological measurements. Agric For Meteorol 150:276-286. doi: 10.1016/j.agrformet.2009.11.012

Otkin JA, Anderson MC, Hain CR, Mladenova IE, Basara JB, Svoboda M (2013) Examining rapid onset drought development using the thermal infrared based Evaporative Stress Index. J Hydrometeorol 14:1057-1074. doi: 10.1175/JHM-D-12-0144.1

Otkin JA, Anderson MC, Hain CR, Svoboda M (2014) Examining the relationship between drought development and rapid changes in the Evaporative Stress Index. J Hydrometeorol 15:938-956. doi: 10.1175/JHM-D-13-0110.1

Priestley CHB, Taylor RJ (1972) On the assessment of surface heat flux and evaporation using large-scale parameters. Mon Weather Rev 100:81-92

Rodriquez JC, et al. (2010) Water use by perennial crops in the lower Sonora watershed. J Arid Environ 74:603-610. doi: 10.1016/j.jaridenv.2009.11.008

Santanello JA, Friedl MA (2003) Diurnal variation in soil heat flux and net radiation. J Appl Meteorol 42:851-862.

Semmens KA, Anderson MC, Kustas WP, Gao F, Alfieri JG, McKee L, Prueger JH, Hain CR, Cammalleri C, Yang Y, Xia T, Sanchez L, Alsina MM, Velez M (2016) Monitoring daily evapotranspiration over two California vineyards using Landsat 8 in a multi-sensor data fusion approach. Remote Sens Environ 185:155-170. doi: 10.1016/j.rse.2015.10.025.

Singleton PL, Maudsley D, (1996) Pattern of water extraction by grapevines on two soils in the Waikato, New Zealand. New Zealand Journal of Crop and Horticulture Science 24:415-424. doi: 10.1080/01140671.1996.9513979

Spano D, Snyder RL, Ducec P, Paw UKT (2000) Estimating sensible and latent heat flux densities from grapevine canopies using surface renewal. Agric For Meteorol 104:71-183. doi: 10.1016/S0168-1923(00)00167-2

Su Z (2002) The surface energy balance system (SEBS) for estimation of the turbulent heat fluxes. Hydrol Earth Sci 6:85-99. doi: 10.5194/hess-6-85-2002.

Sun L, Gao F, Anderson MC, Kustas WP, Alsina MM, Sanchez S, Sams B, McKee L, Dulaney W, White WA, Alfieri JG, Prueger JH, Melton F, Post K (2017) Daily mapping of $30 \mathrm{~m} \mathrm{LAI}$ and NDVI for grape yield prediction in California vineyards 9:1-18. doi: 10.3390/rs9040317.

Tang R, Li Z, Sun X (2013) Temporal upscaling of instantaneous evapotranspiration: An intercomparison of four methods using eddy covariance measurements and MODIS data 138:102-118. doi: 1016/j.rse.2013.07.001 
Teixeira AH, de C, Bastiaanssen WGM, Bassoi LH (2007) Crop water parameters of irrigated wine and table grapes to supper water productivity analysis in the Sao Francisco river basin, Brazil. Agric Water Manage 94:31-42. doi: 10.1016/j.agwat.2007.08.001

Trambouze W, Bertuzzi P, Voltz M (1998) Comparison of methods for estimating actual evapotranspiration in a row-cropped vineyard. Agr For Meteorol 91:193-208

Twine TE, Kustas WP, Norman JM, Cook DR, Houser P, Meyers TP, Prueger JH, Starks PJ, Wesely ML (2000) Correcting eddy-covariance flux underestimates over a grassland. Ag Forest Meteorol 103: 279-300. doi: 10.1016/S0168-1923(00)00123-4

Van Leeuwen C, Tregoat O, Chone X, Bois B, Pernet D, Gaudillé JP (2009) Vine water status is a key factor in grape ripening and vintage quality for red bordeaux wine. How can it be assessed for vineyard management purposes? J Int des sciences de la vigne et du vin 43:121-143. doi: 10.20870/oeno-one.2009.43.3.798

Whelan BM, McBratney AB, Minasny B (2002) VESPER 1.5 - Spatial prediction software for precision agriculture. In P.C. Robery, R.H. Rust \& W.E. Larson (eds) Precision Agriculture, Proceedings of the $6^{\text {th }}$ International Conference of Precision Agriculture, ASA/CSSA/SSSA, Madison, Wisc., 14p.

Williams LE, Matthews MA (1990) Grapevines. In: Stewart BA, Nielsen DR (eds) Agronomy monograph \#30 irrigation of agricultural crops. ASA-CSSA-SSSA Publishers, Madison, pp 1019-1055

Williams LE, Dokoozlian NK, Wample RL (1994) Grape. In: Shaffer B, Anderson PC (eds) Handbook of environmental physiological of fruit crops. Volume 1. Temperate crops. CRC Press, Orlando, pp 83-133

Xia T, Kustas WP, Anderson MC, Alfieri JG, Gao F, McKee L, Prueger JH, Geli HME, Neale CMU, Sanchez L, Alsina MM, Wang Z (2016) Mapping evapotranspiration with high-resolution aircraft imagery over vineyards using one- and two-source modeling schemes. Hydrol Earth Syst Sci 20:1523-1545. doi: 10.5194/hess-20-1523-2016.

Yunusa IAM, Walker RR, Guy IR (1997) Partitioning of seasonal evapotranspiration from a commercial furrow-irrigated Sultana vineyard. Irrig Sci 18:45-54. doi: 10.1007/s002710050043

Yunusa IAM, Walker RR, Lu P (2004) Evapotranspiration components form energy balance, sapflow and microlysimetry techniques for an irrigated vineyard in inland Australia. Agric For Meteorol 127:93-107. doi: 10.1016/j.agwat.2011.03.006

Zhang Y, Kang S, Li F, Tong L, Du T (2010) Variation in vineyard evapotranspiration in an arid region of northwest China. Agric For Meteorol 97:1898-1904. doi:

10.1016/j.agwat.2010.06.010 
Zhang Y, Kang S, Ward EJ, Ding R, Zhang X, Zheng R, (2011) Evapotranspiration components determined by sap flow and microlysimetry techniques of a vineyard in northwest China: dynamics and influence factors. Agric For Meteorol 98:1207-1214. doi:

10.1016/j.agwat.2011.03.006 